\title{
اتجاهات الشباب الجامعي نحو إعلانات شركات الهاتف المحمول في مواقع التواصل الاجتماعي(الفيس بوك إنموذجاً)
}

\author{
أ.م.د. محمد جياد زين الدين
}

كلية الإعلام/ الجامعة العراقية

\section{المستخلص}

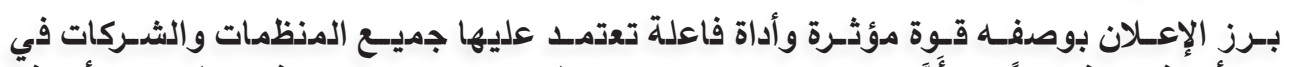

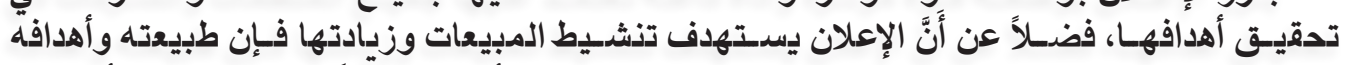

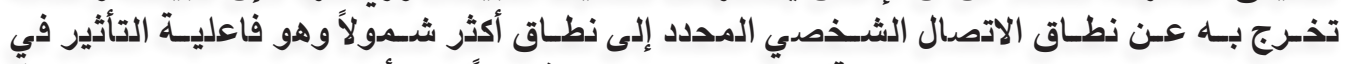

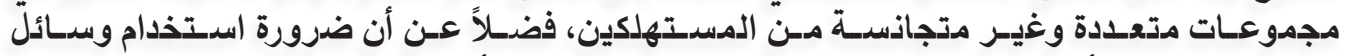

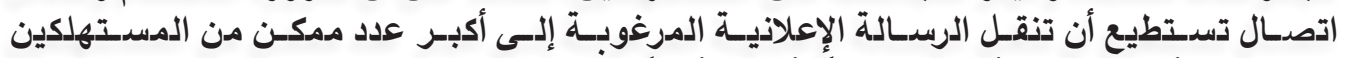

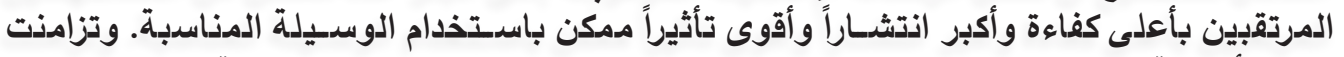

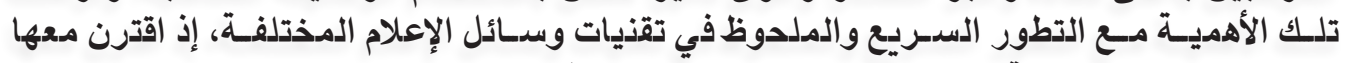

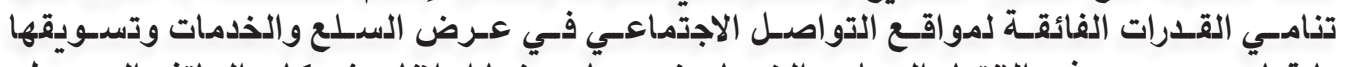

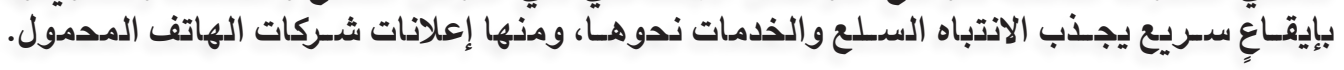

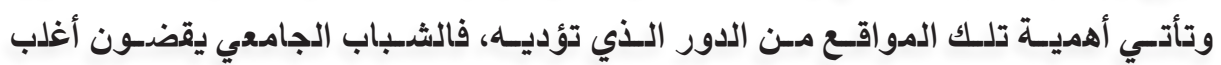

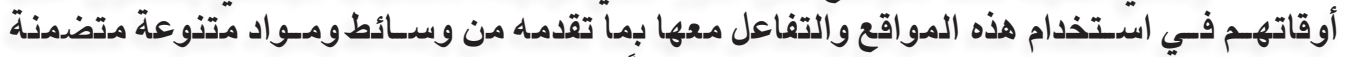

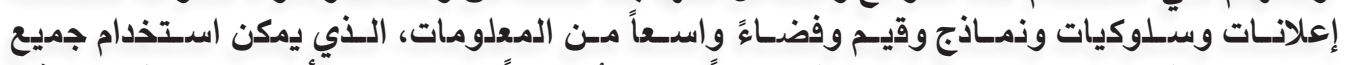

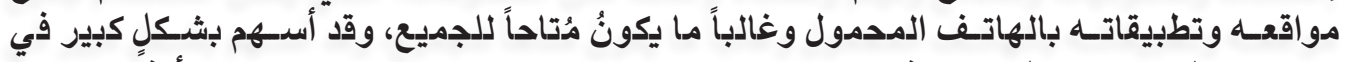

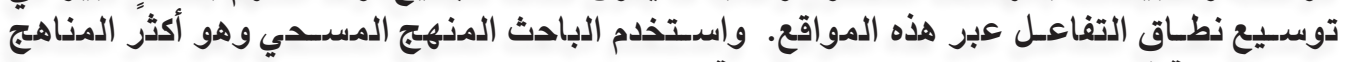

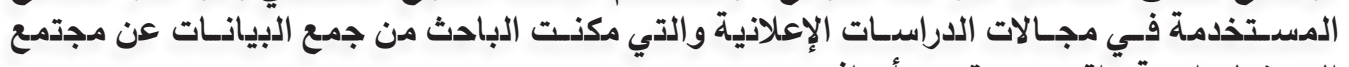

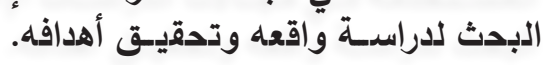

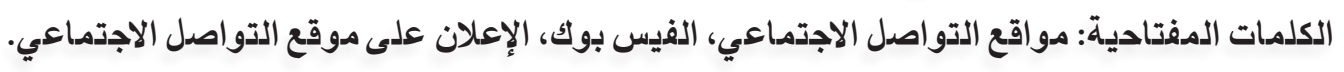

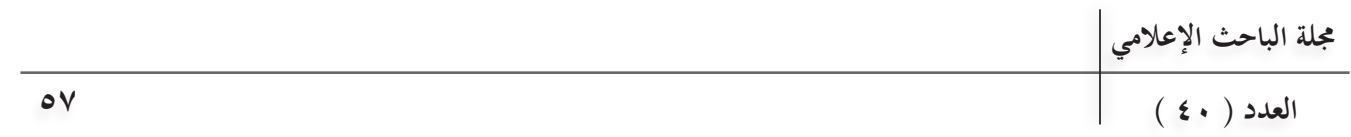


University youth attitudes towards mobile phone Companies advertisements in Social networking sites(facebook as sample)

\author{
Prof. Assitant. Doctor Mohammed Jiad Zain AL-Deen \\ Media College: AL-Iraqia University
}

\title{
Abstract
}

The advertising has emerged as an effective force and an effective instrument up on with all organizations and companies depend on achieving their goals. In additional to the need to use promote sales, The nature and objective of advertising go beyond the scope of specific personal communication to a broader and more effective range for consumers from multiple groups and combination play need to use as well as the need to use means of communication than com convey the massage more professional, The coincides with the rapid and remarkable development of all different media technologies and as much as possible social networking sites including mobile phone companies.

The impotent of these sites from the role played by University youth spend most of their time in the use of these sites and interest with them by providing a variety of media and dives material including advertising be have or. Model, values and space broad information that can be used in all mobile applications and these expanded interaction.

The researcher used the survey approach by collecting data on research community to study relating and achieve its goals.

Key words: social media sites, The Face book, Advertising on Social media.

\begin{tabular}{|c|c|}
\hline & مجلة الباحث الإعلامي \\
\hline $0 \wedge$ & العدد ( • ؛ ) \\
\hline
\end{tabular}




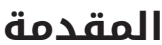

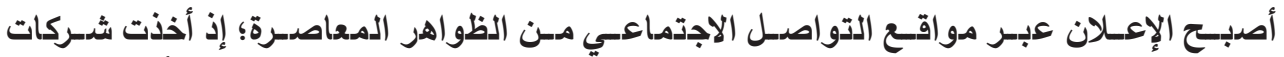

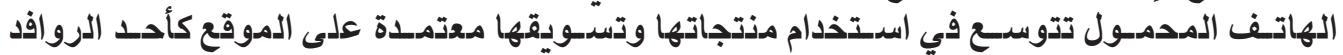

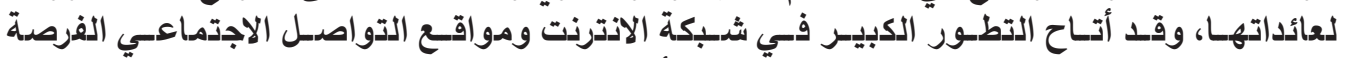

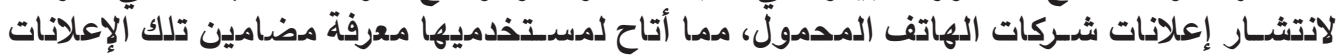

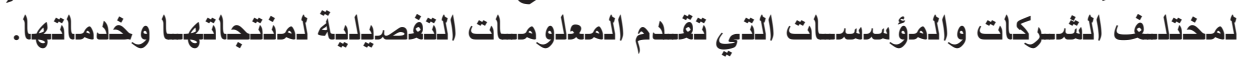

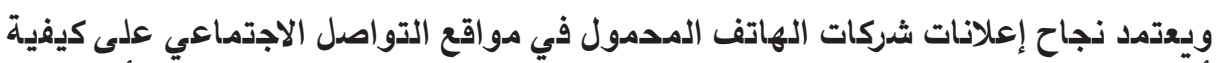

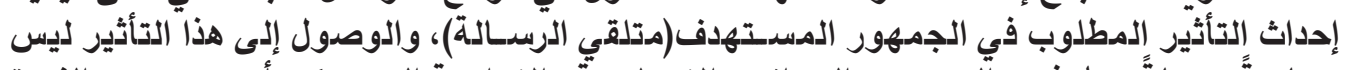

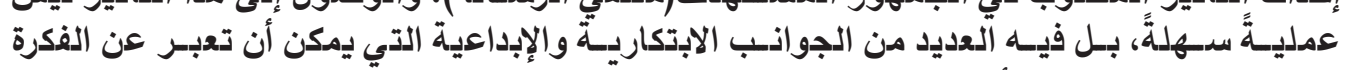

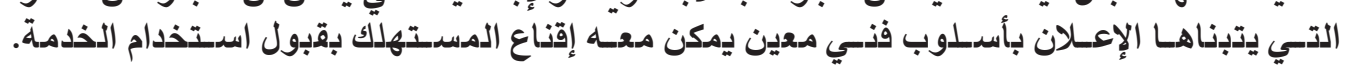

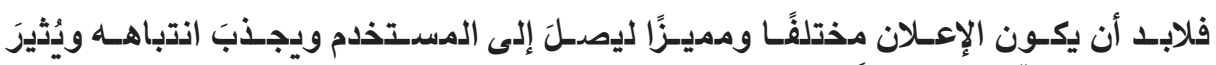

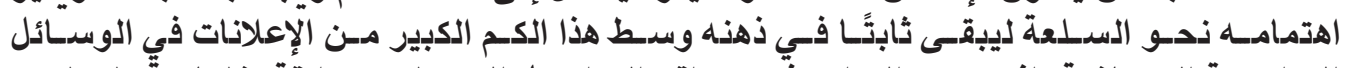

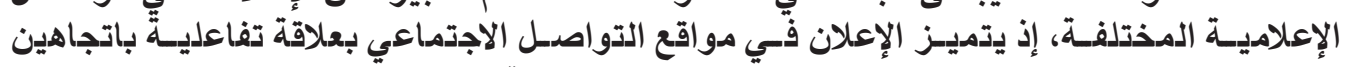

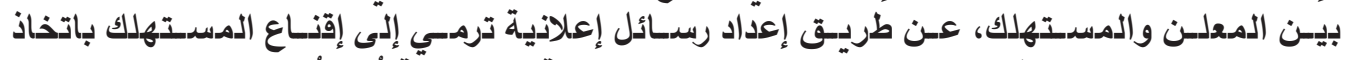

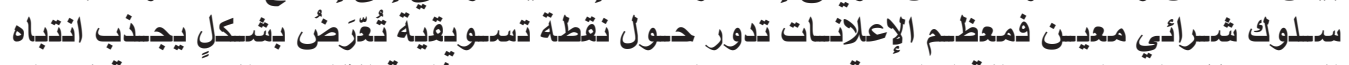

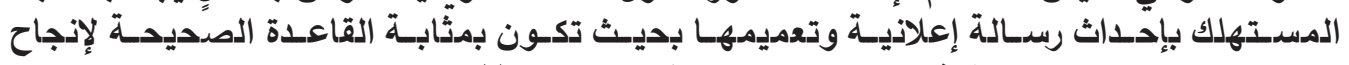

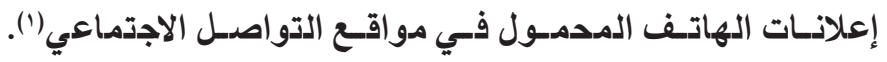

الإطار المنهجي أولاً: مشكلة البحث

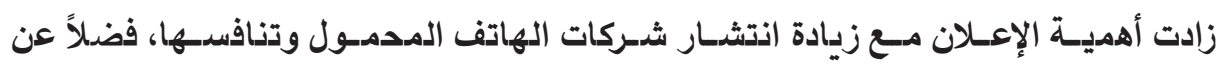

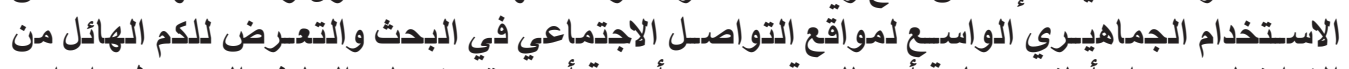

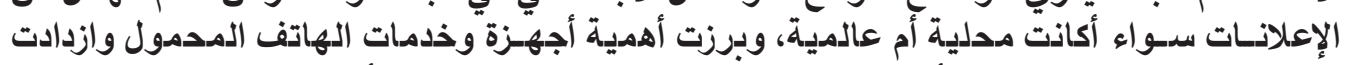

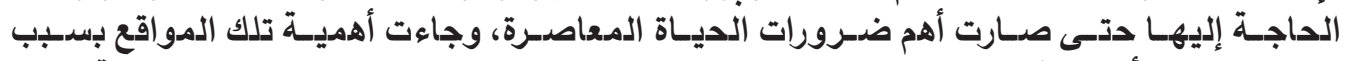

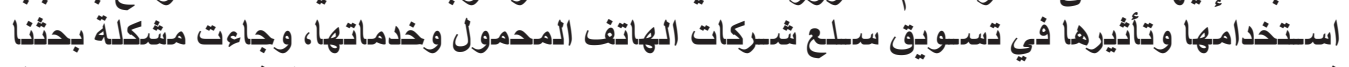

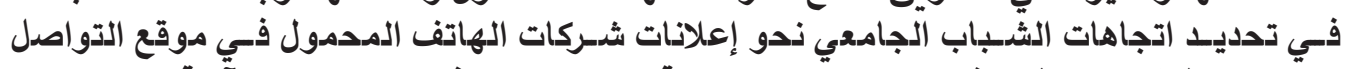

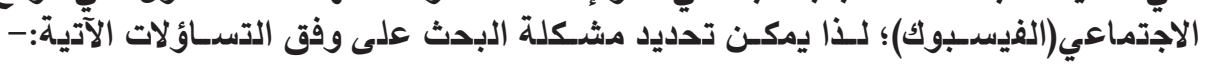

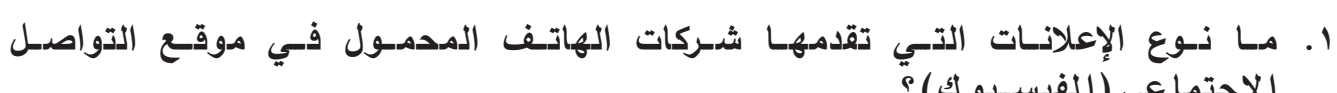

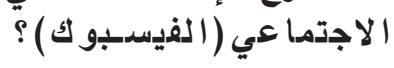

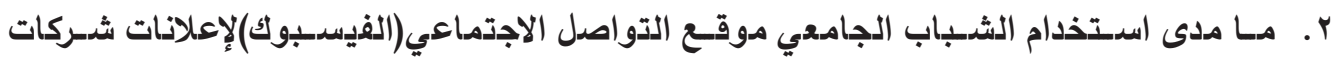

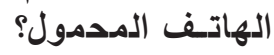

r. ما مدى اعتماد المبحوثين على مصادر المعلومات عند اتخاذ قرار شراء الهاتف المحمول؟

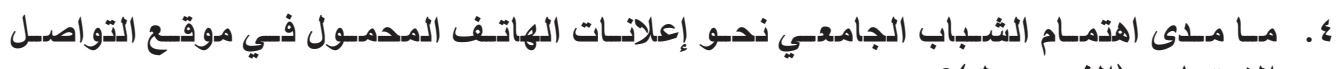

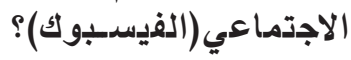




\section{ثانياً: أهمية البحث}

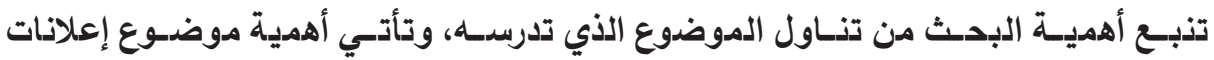

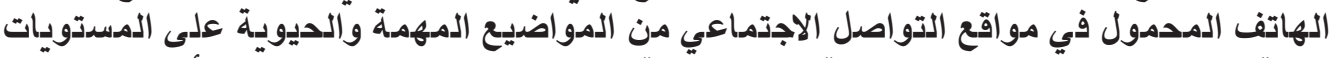

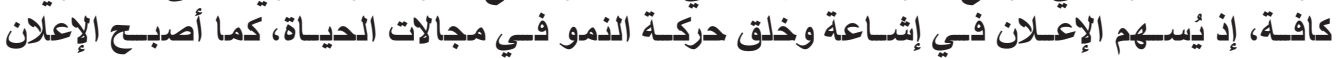

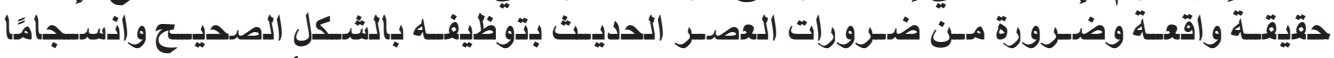

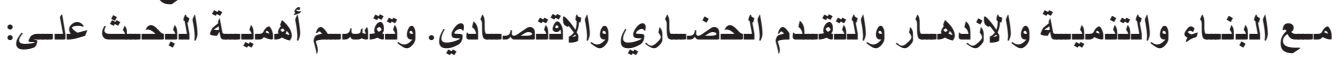

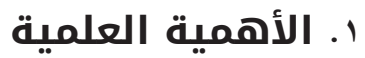

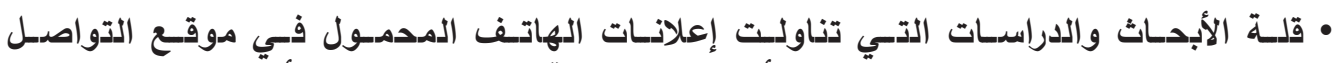

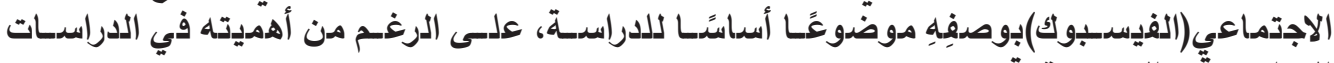

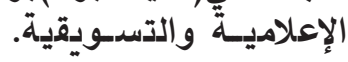
• معرفة أبرز المهلامح العامة لإعلانات الهاتف المحمول قي موقع التواصل الاجتماعي(الفيسدبوك). r. الأهمية العملية

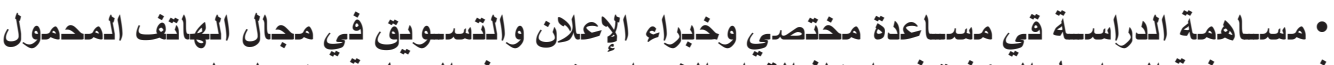

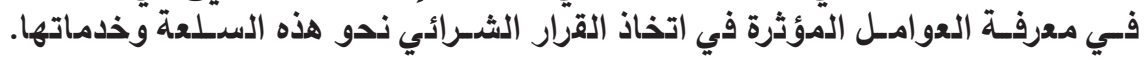

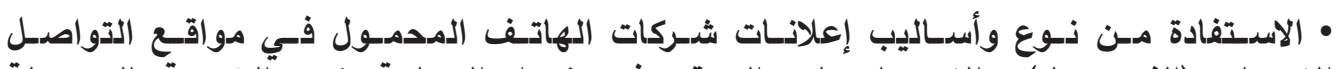

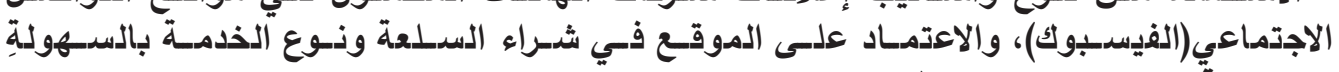

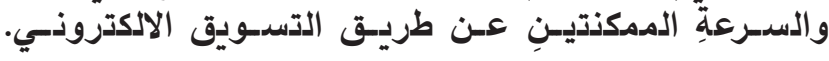

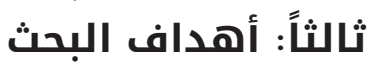
يرمي إلى تحقيق الآتي:

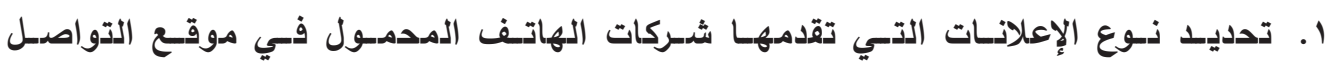

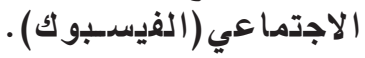

ץ . م معرفة اعتماد المبحوثين على مصادر المعلومات عند اتخاذ قرار شراء الهاتف المحمول.

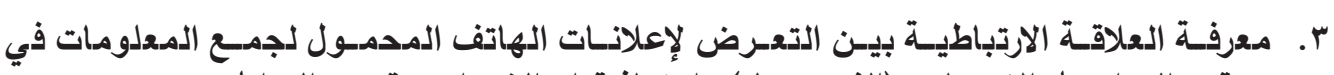

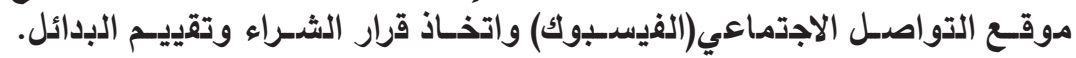
ع. . معرفـة نـوع السدـلـع والخدمـات التـي يحـرص المبحوثون علـى متابعتها في موقـع التواصل الاجتماءي(الفيسدبولك).

\section{رابعاً: نوع البحث ومنهجه}

يُعد هذا البحث من البحوث الوصفية التي تسدتخدم منهج المسدح بوصفه أنسدب المناهج العلدية

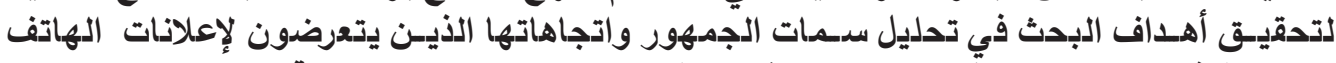

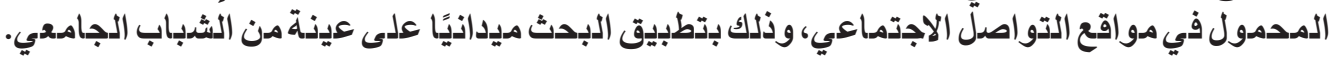

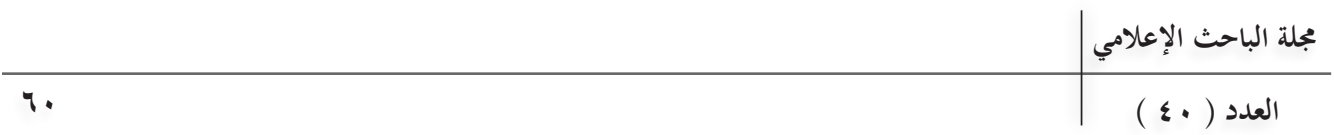




\section{خامسًا: مجتمع البحث وعينته}

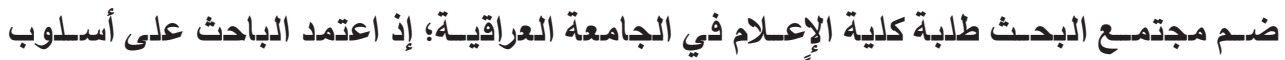

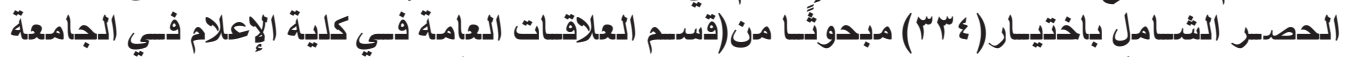

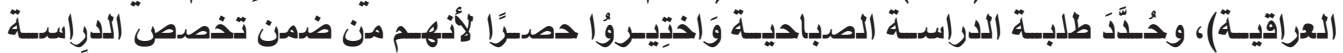

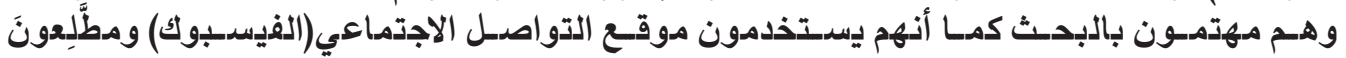

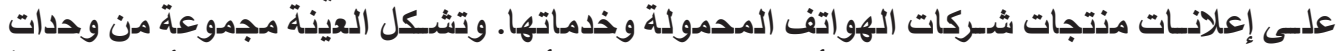

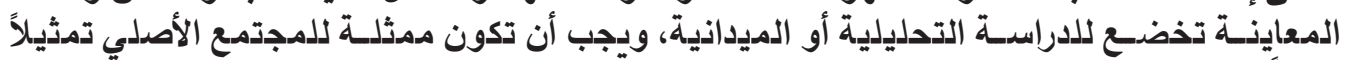

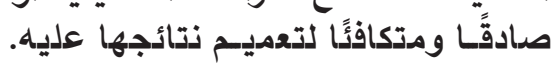

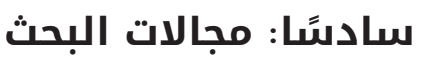

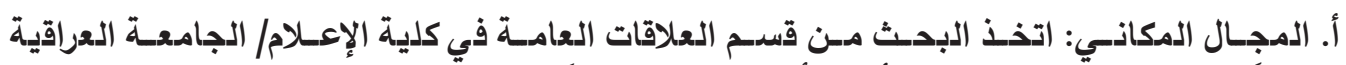

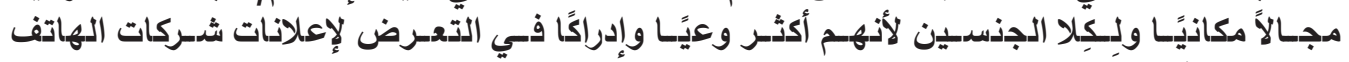

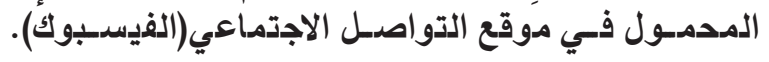

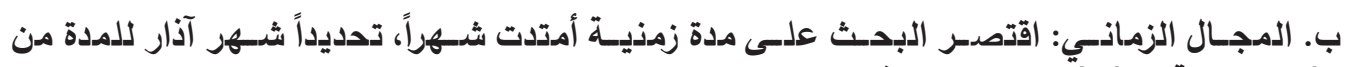

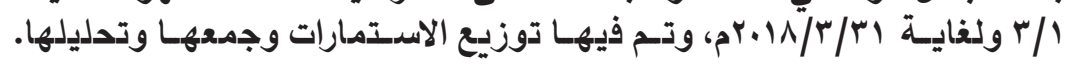

\section{سابعاً: صدق الأداة}

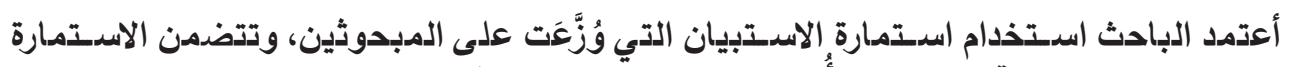

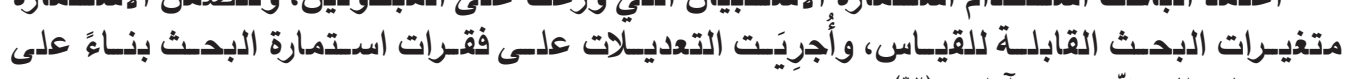

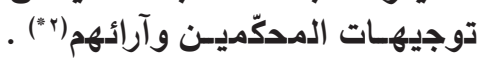

\section{ثامنًا: دراسات سابقة}

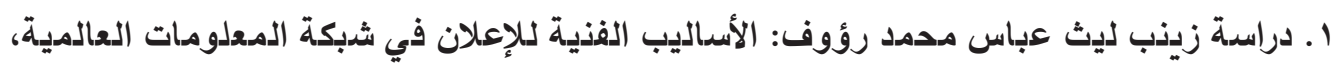

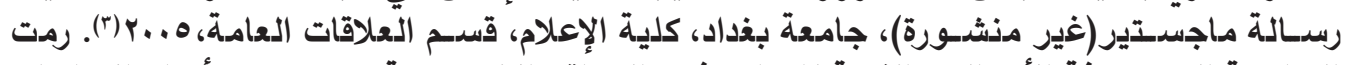

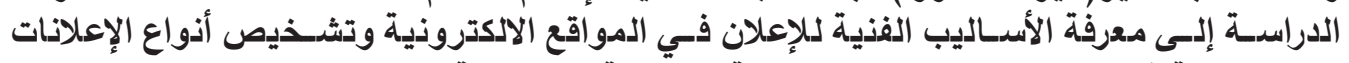

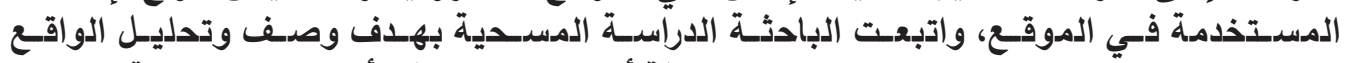

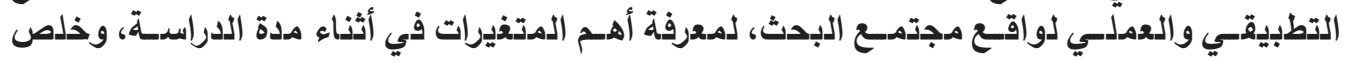

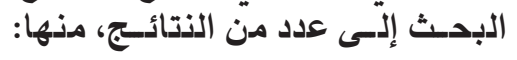

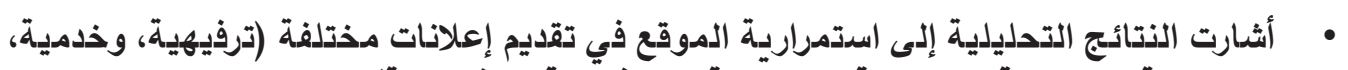

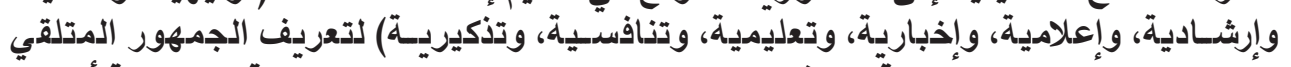

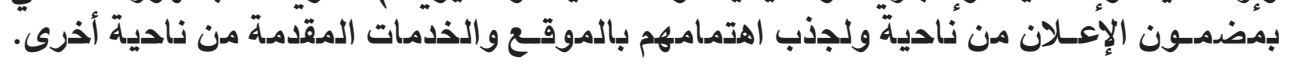

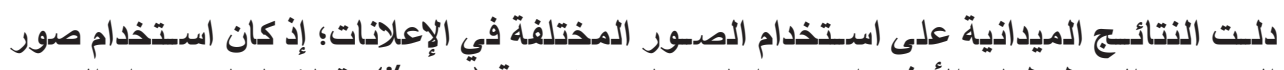

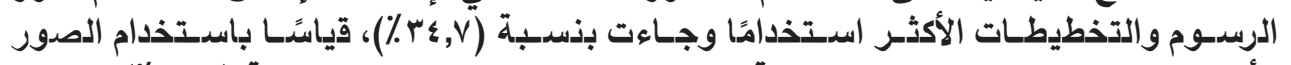

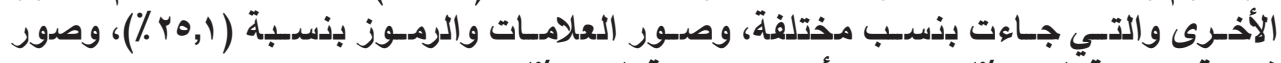

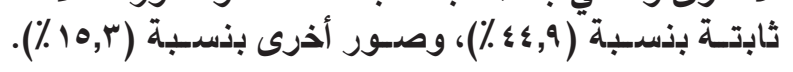




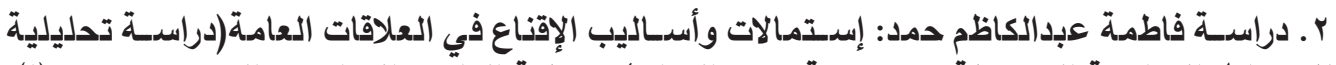

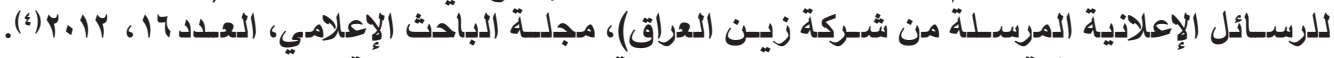

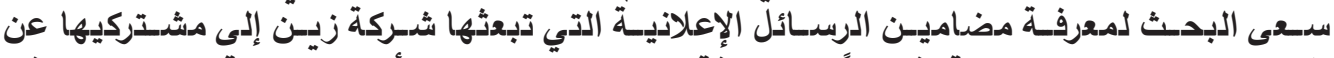

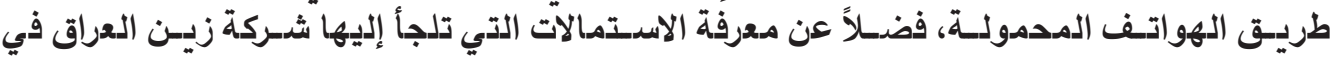

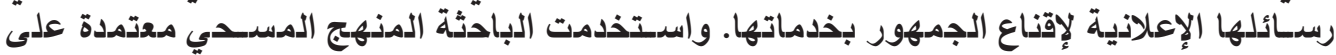

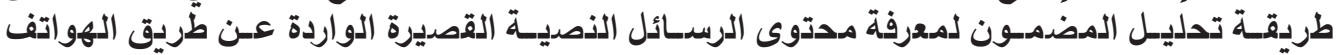

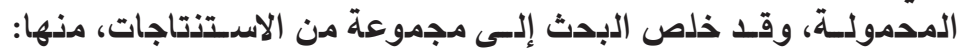

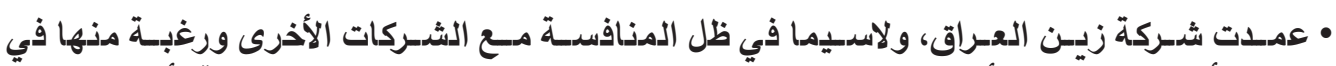

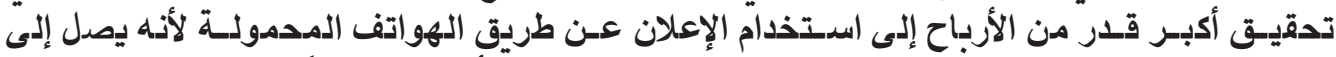

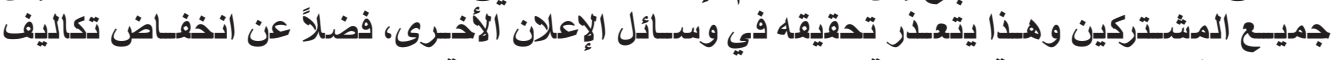

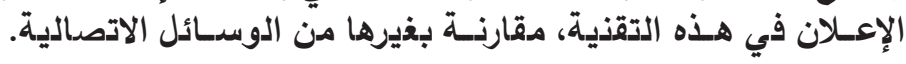

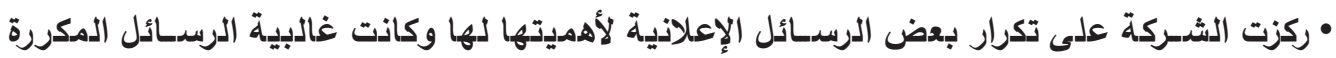

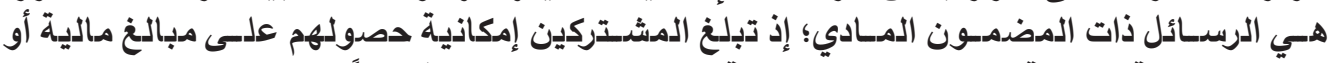

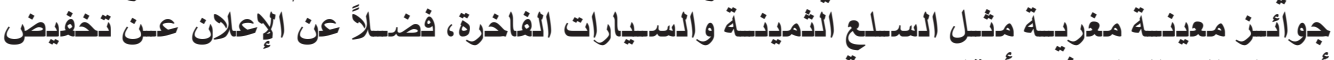

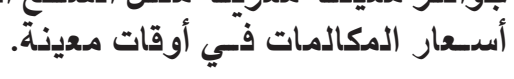

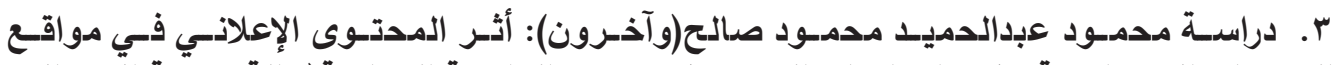

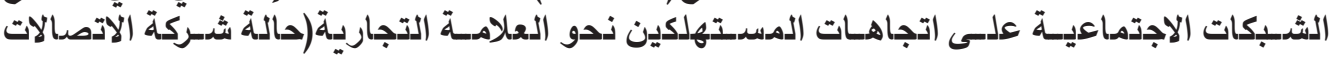

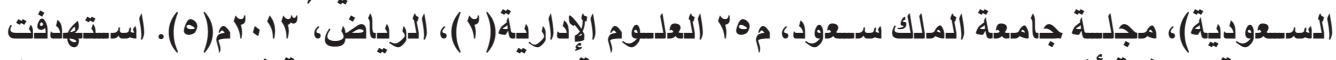

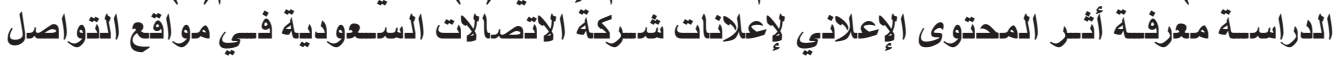

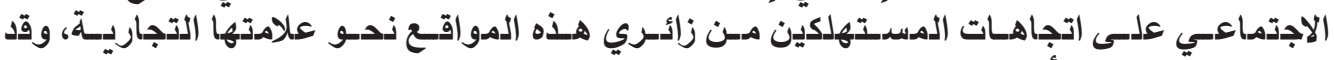

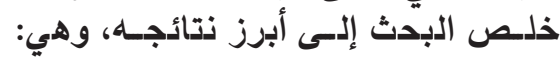

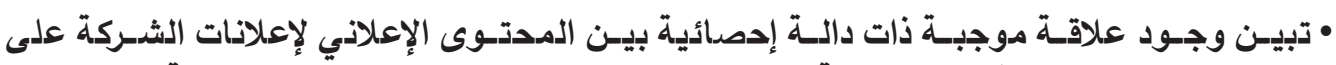

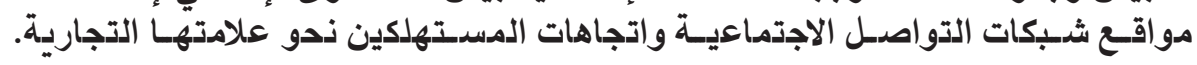

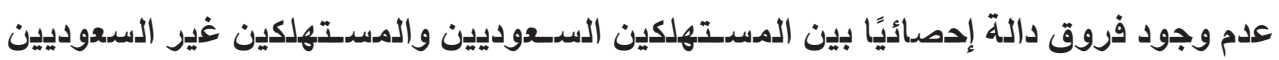

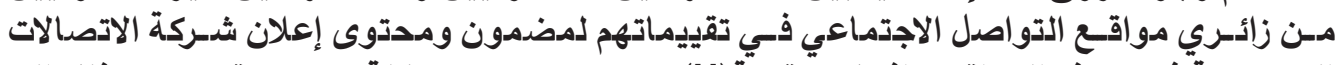

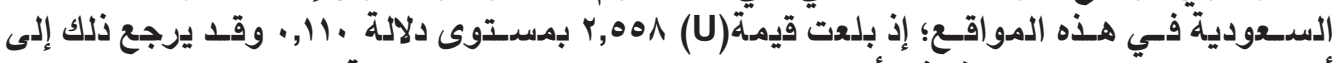

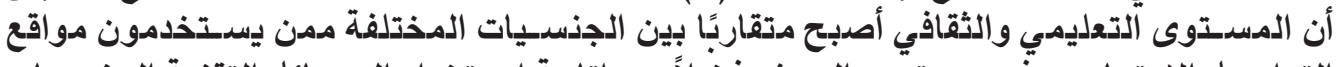

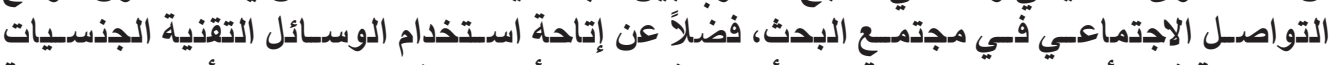

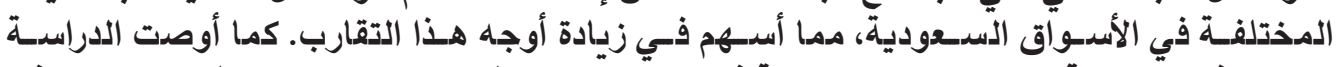

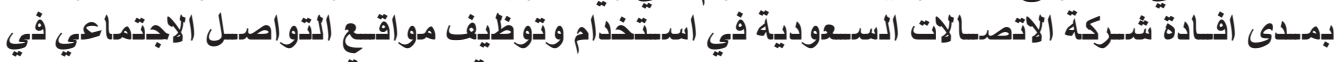

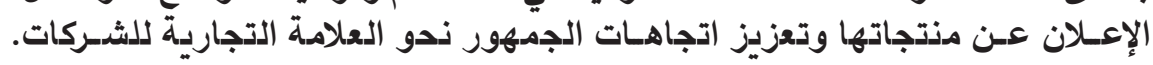

4. Hyejin Bang \& Wei-Na Lee: Consumer Response to Ads in Social Network Sites; An Exploration into the Role of Ad Location and Path, Paper Presented at the annual meeting of the Association for Education in Journalism and Mass Communication, Renaissance Hotel, Washington DC, 2013(6):

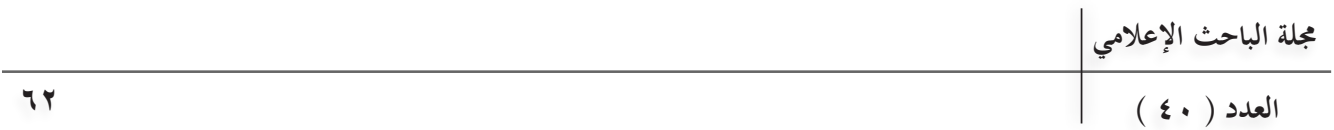


ترمي الدراسـة إلى فهم تأثير موقع الإعلانات المقدمة على الفيس بوك، المسدسار الذي تصدل

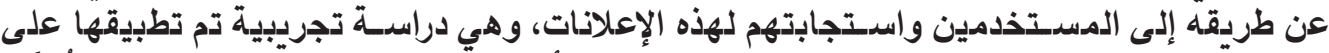

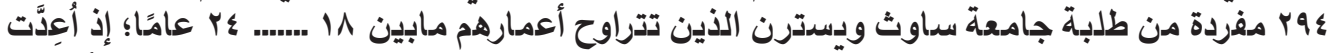

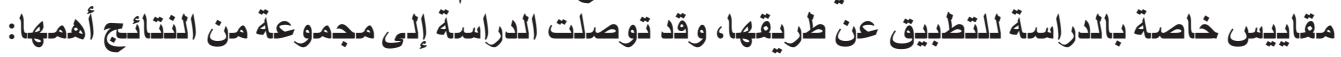

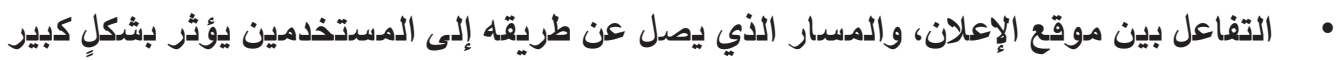

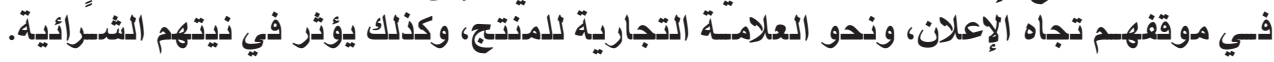

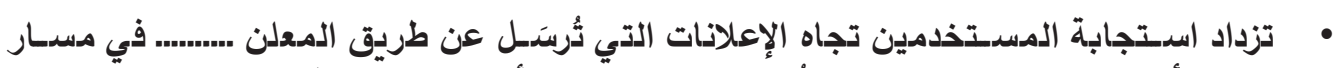

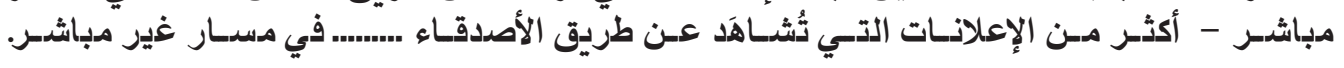

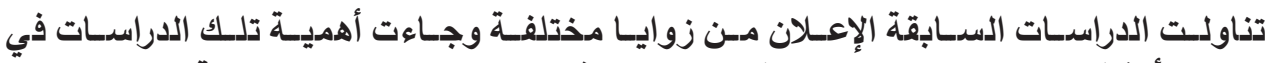

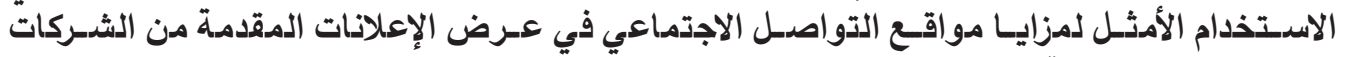

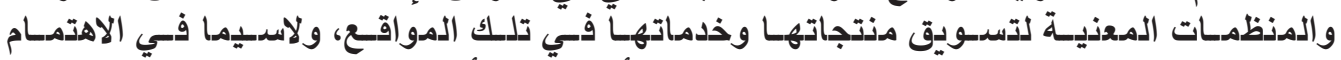

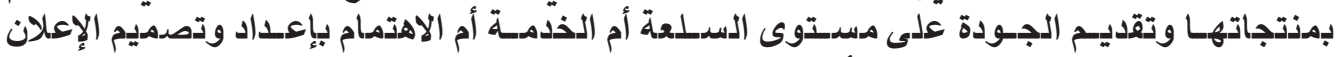

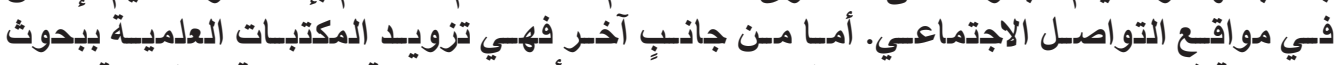

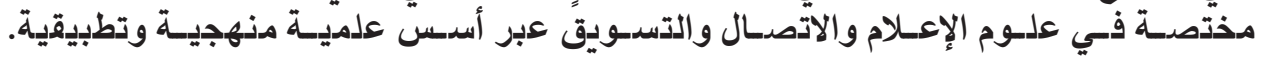

\section{ـمواقع التواصل الاجتماعي}

\section{أولاً: مواقع التواصل الاجتماعي.}

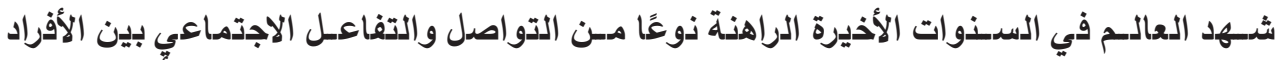

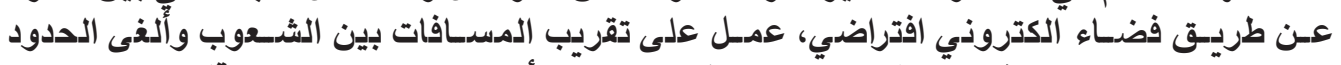

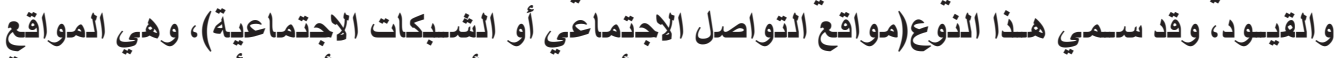

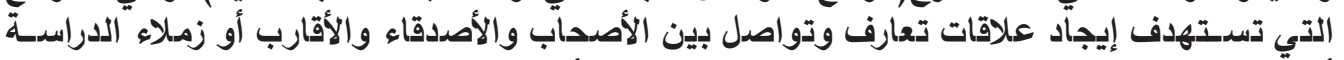

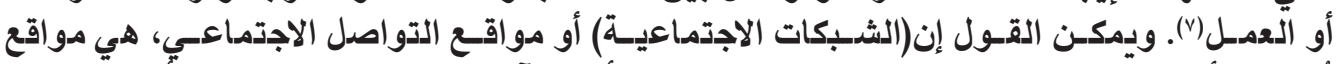

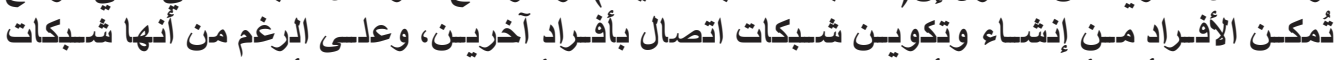

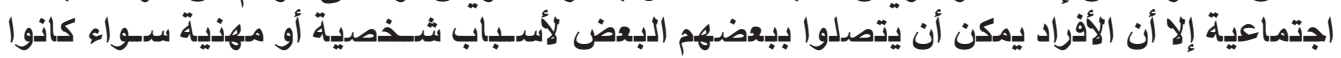

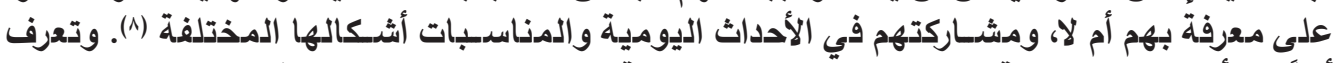

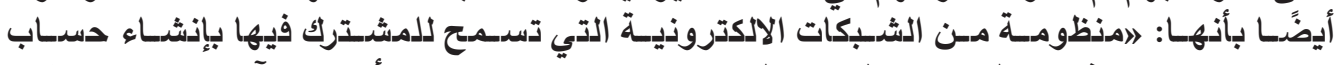

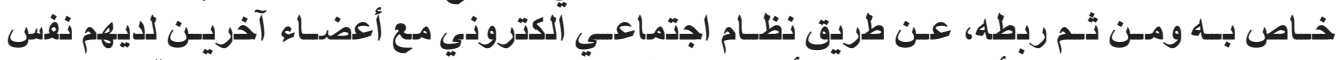

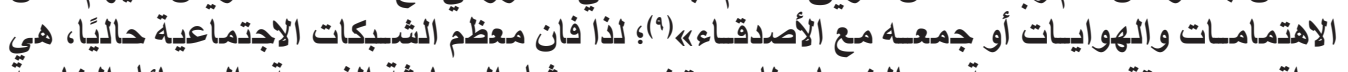

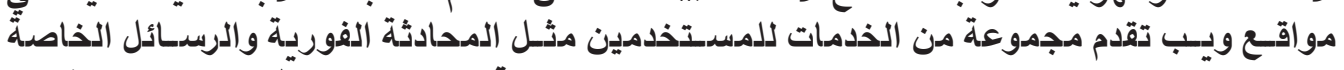

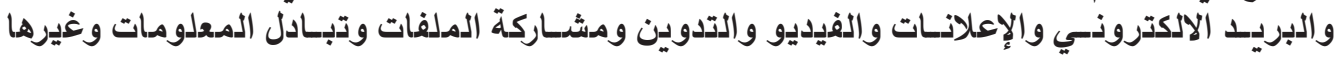

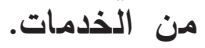

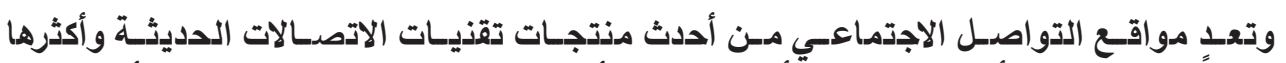

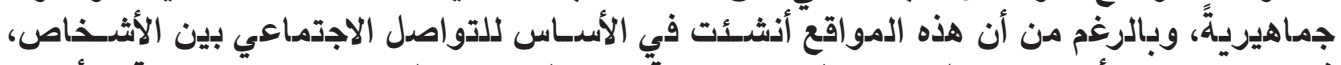

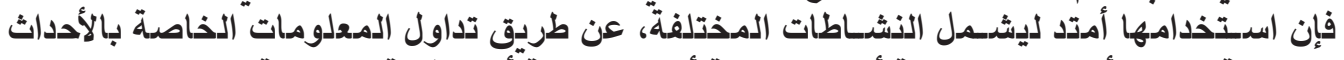

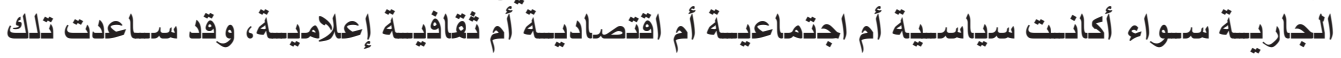




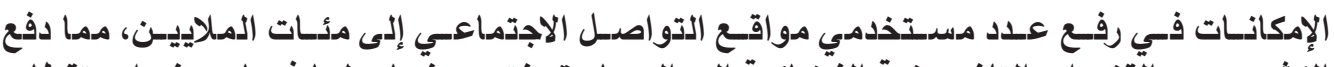

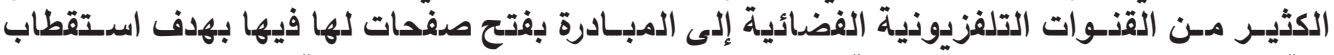

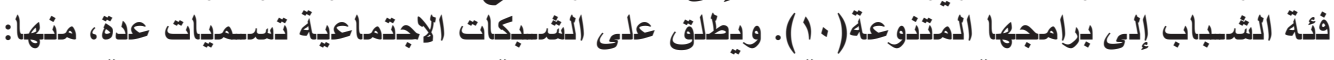

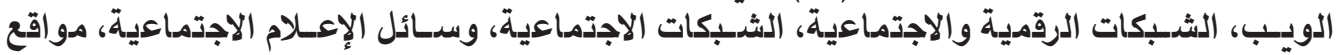

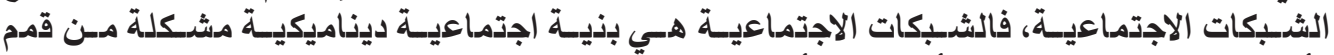

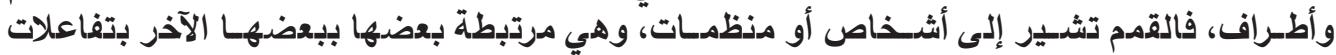

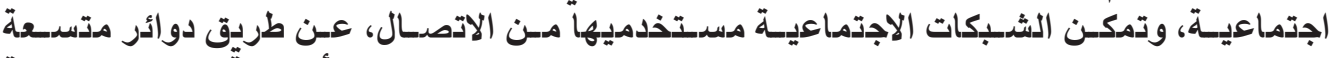

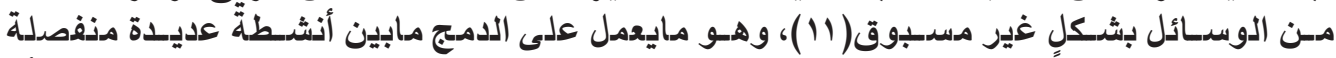

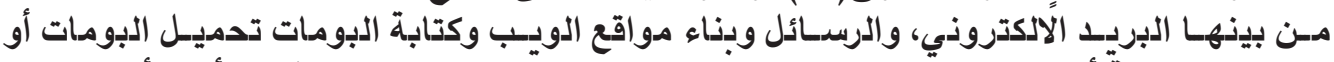

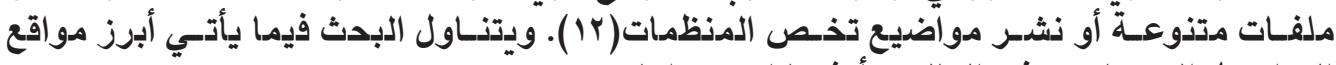

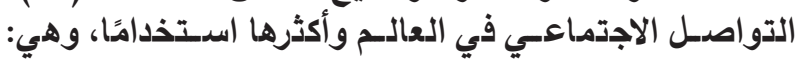

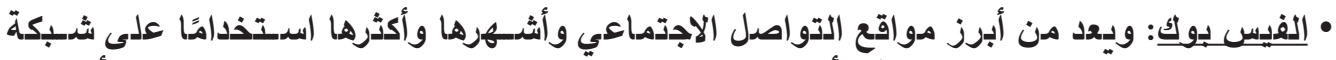

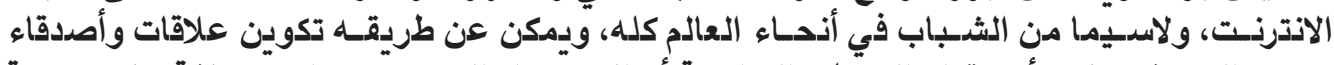

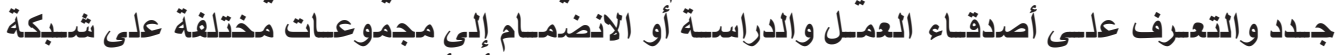

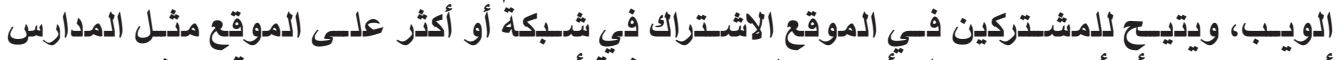

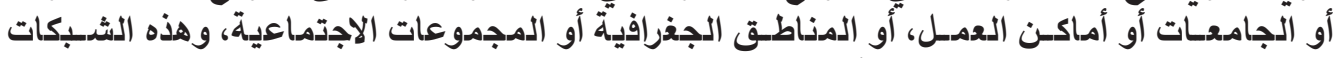

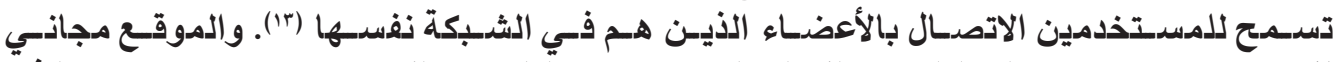

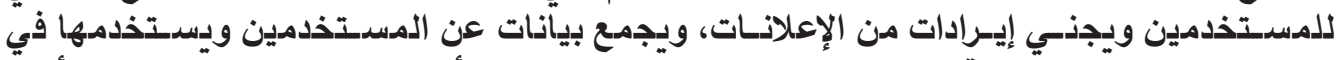

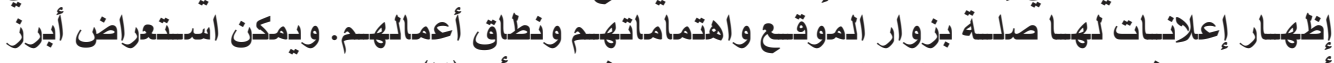

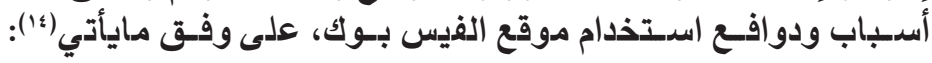

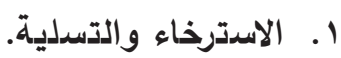

r. ب. تبادل المعلومات والأفكار والآراء.

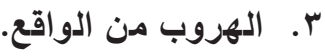

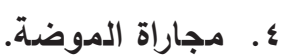

ه. إقامة علاقات وتكوين صداقات جديدة.

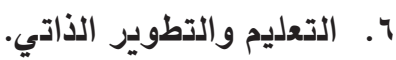

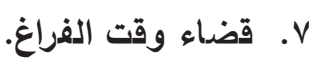

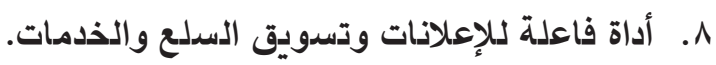

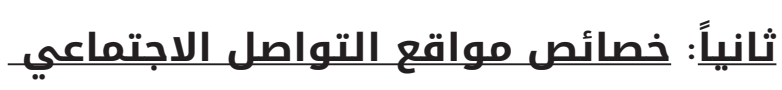

تتصفمو اقع التواصل الاجتماعي بعددمن الخصائصو السدمات، وهي علىوفق الشكل الآتي(10) :

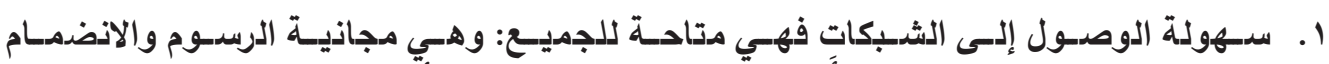

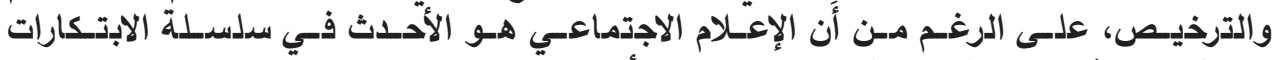

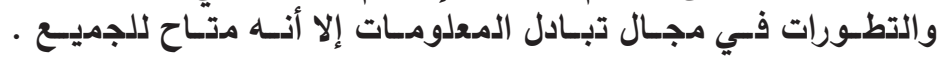




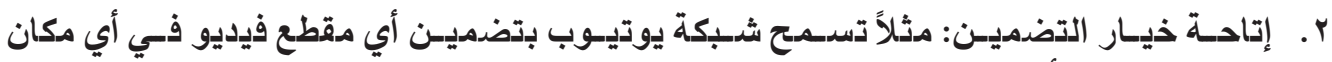

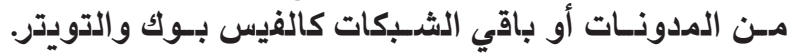

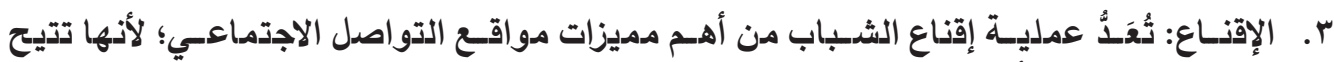

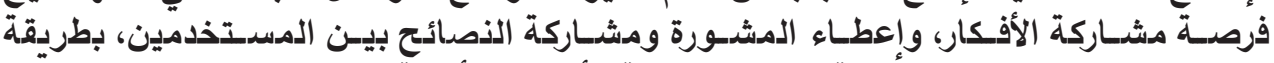

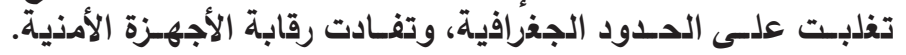

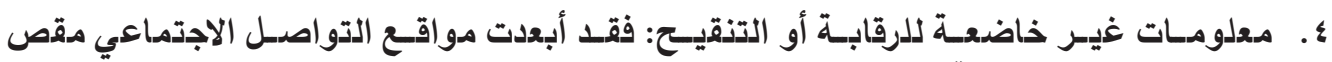

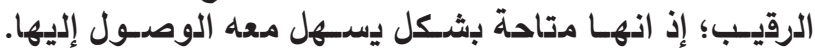

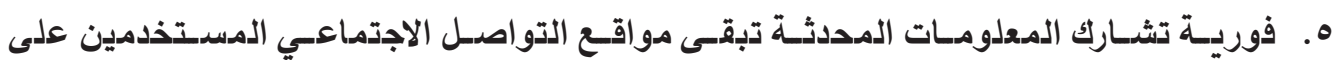

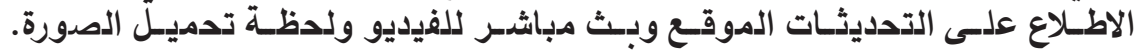
4. اتصـالات متعـدةدة توفرهـا: مثـل المدونـات الكبيـرة ومدونــات صغيـرة، ومواقـع اجتماعيـة

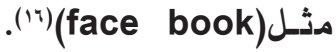

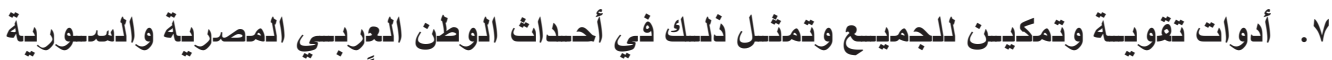

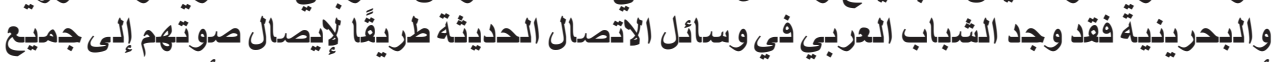

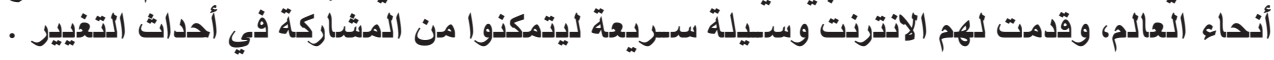

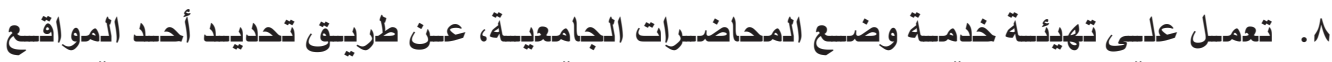

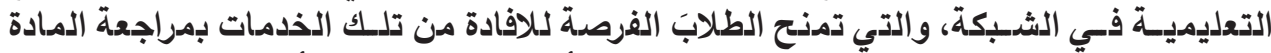

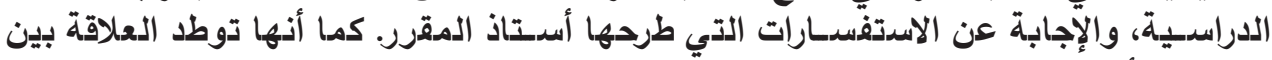

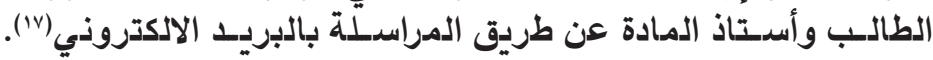

\section{ثالثاً:الإعلان في مواقع التواصل الاجتماعي}

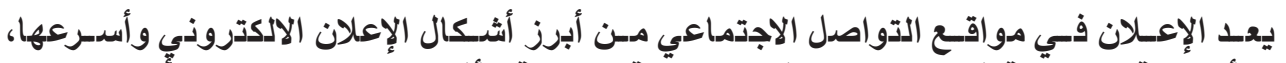

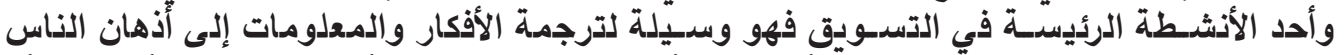

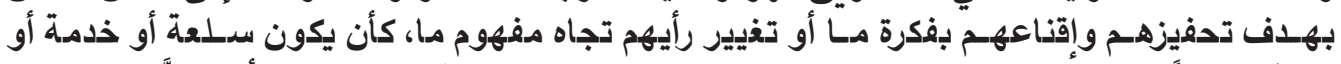

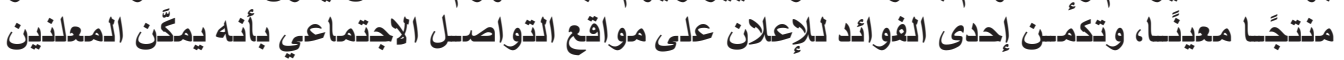

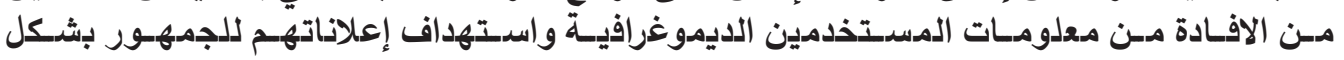

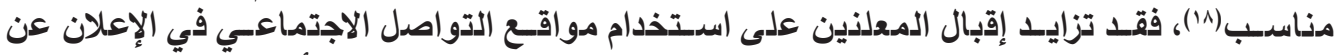

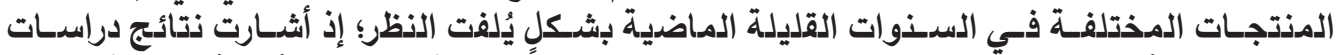

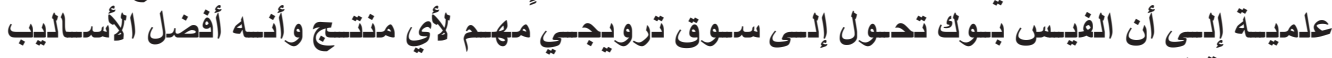

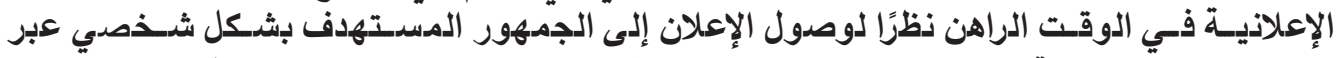

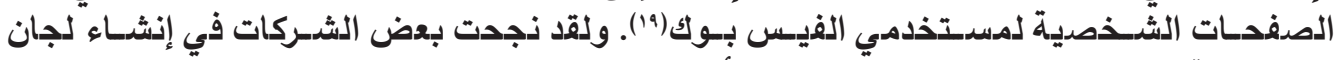

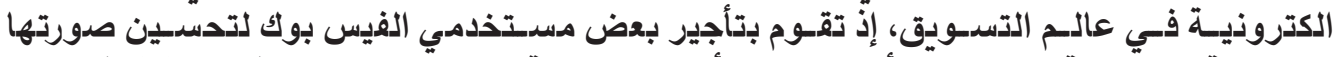

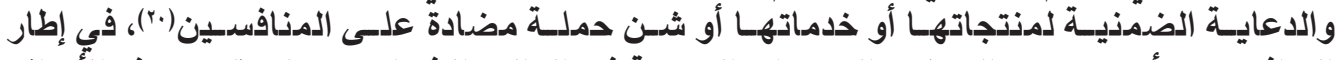

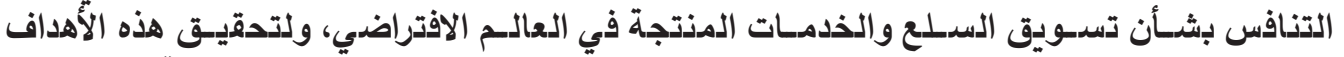

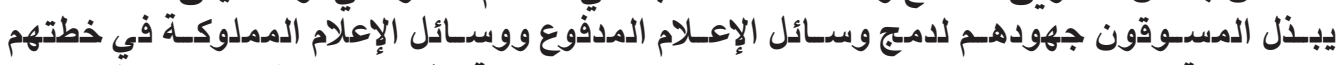

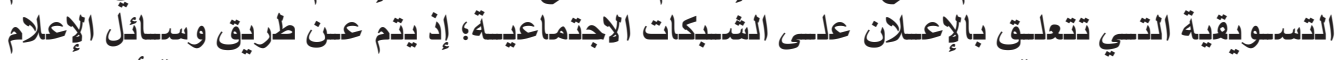

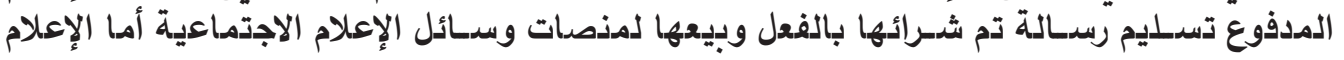




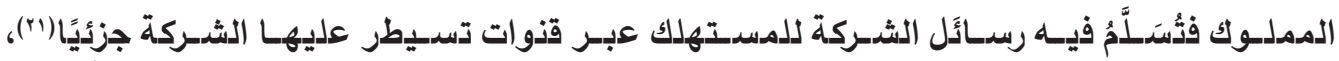

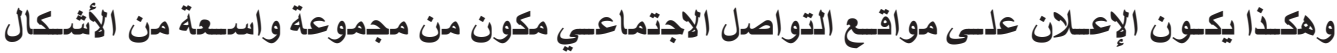

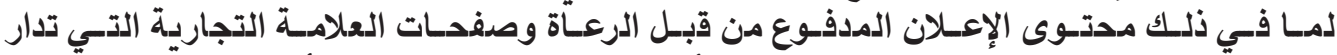

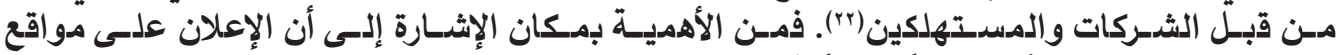

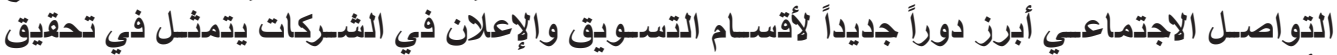

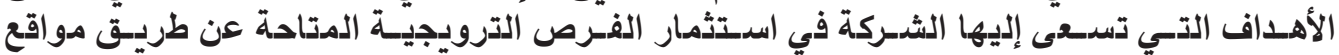

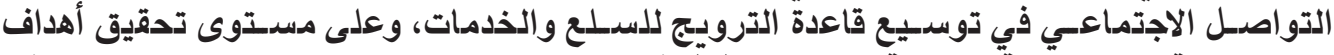

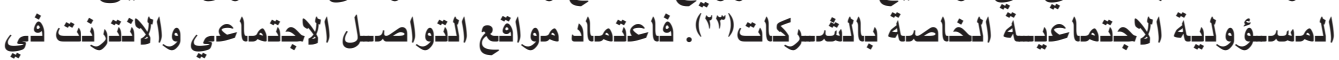

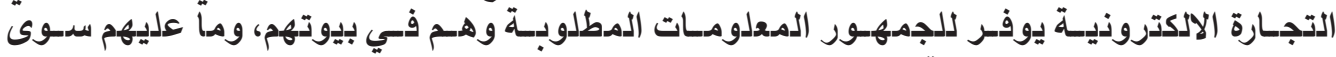

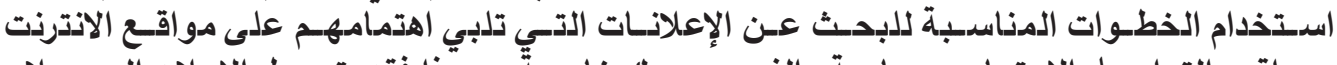

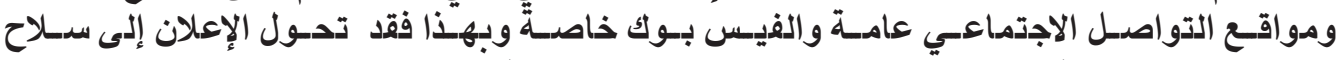

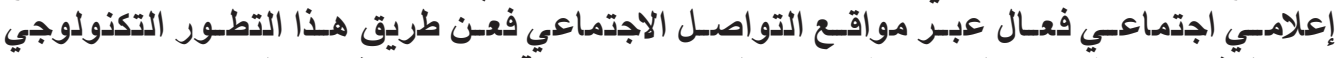

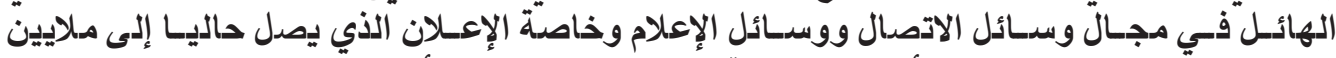

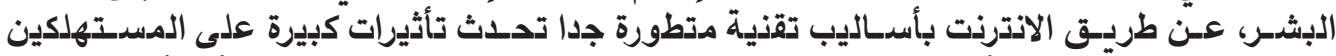

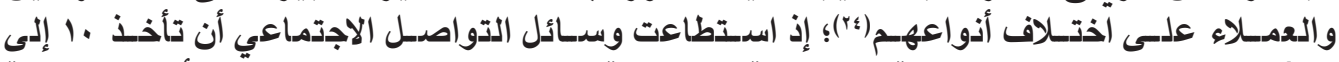

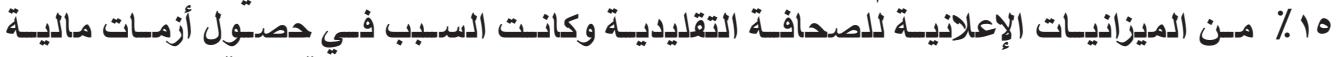

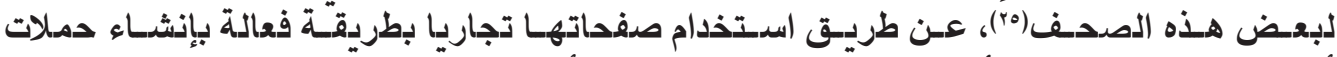

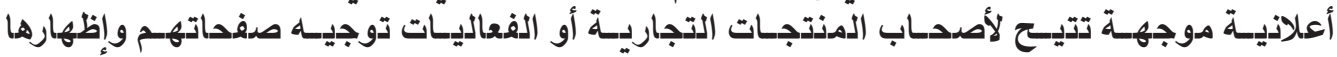

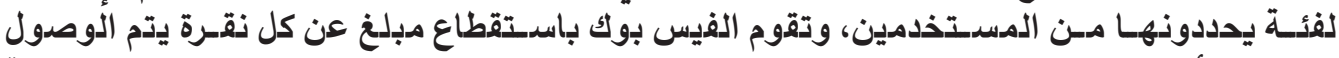

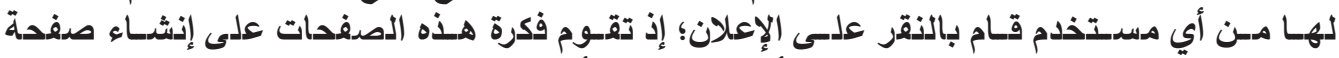

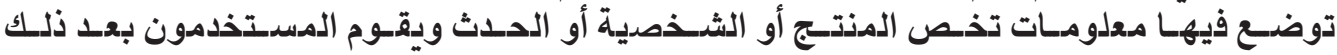

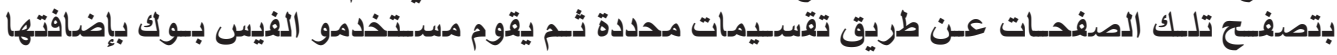

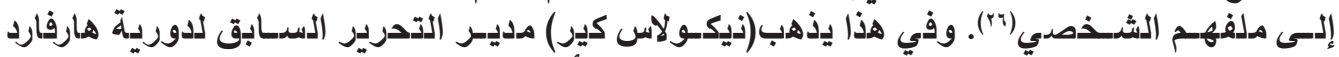

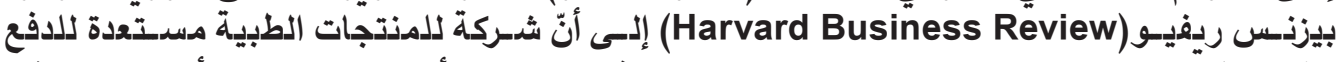

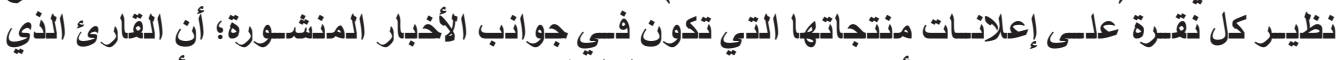

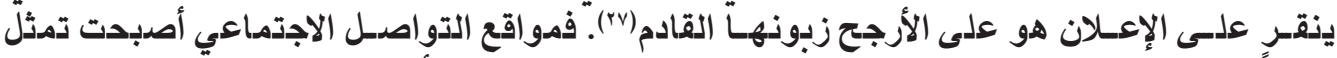

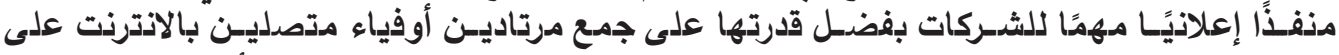

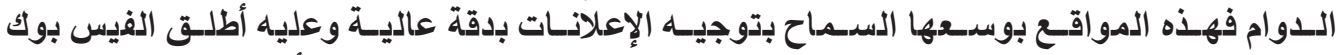

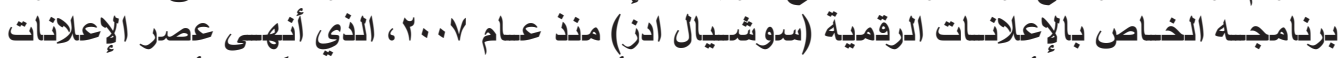

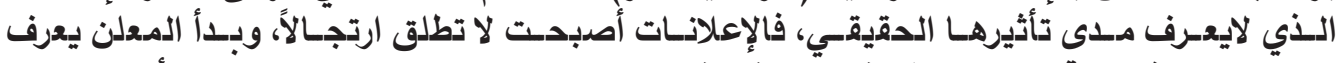

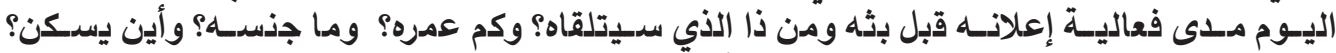

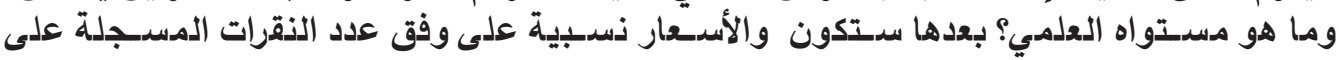

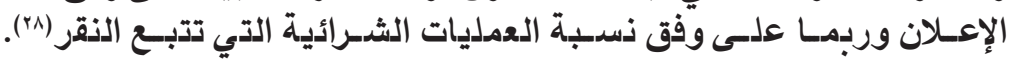

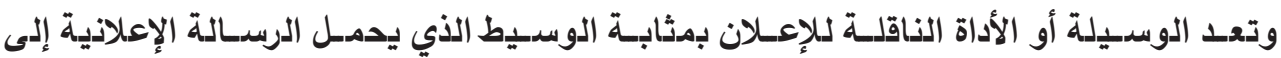

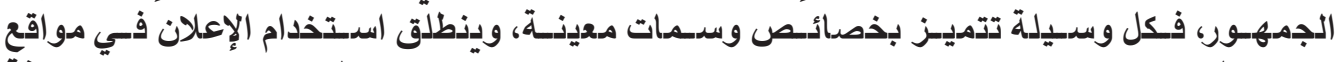

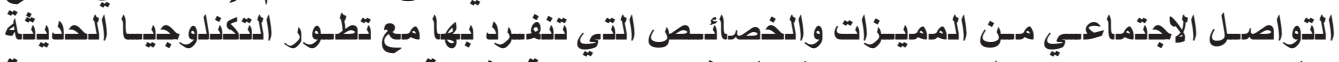

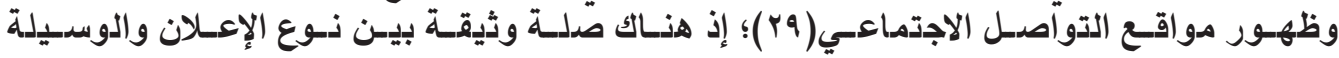




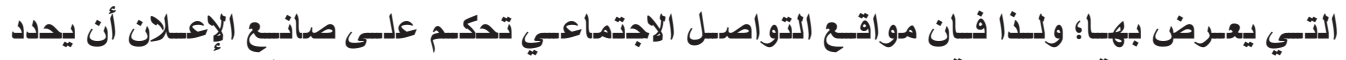

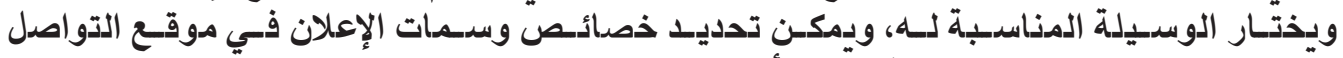

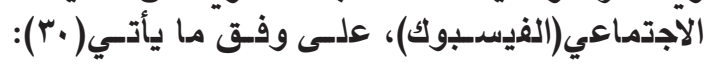

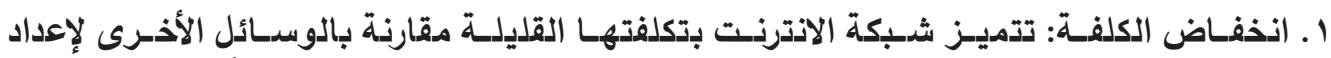

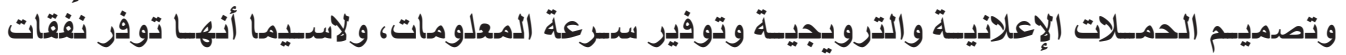

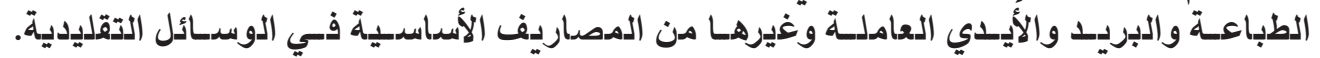

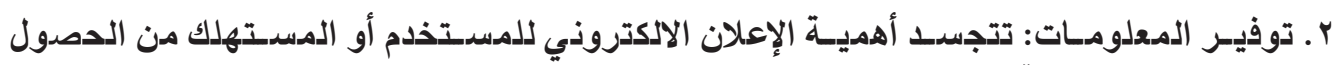

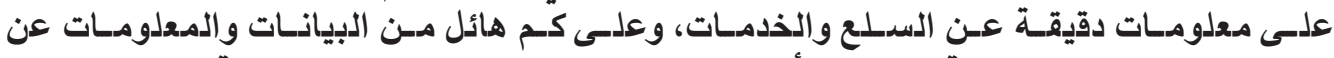

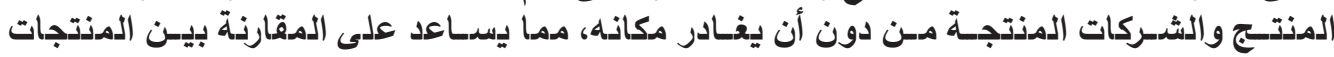
المنافسـة من حيث السـعر والثكل.

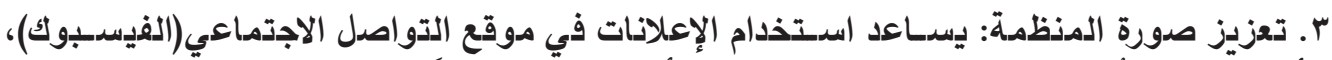

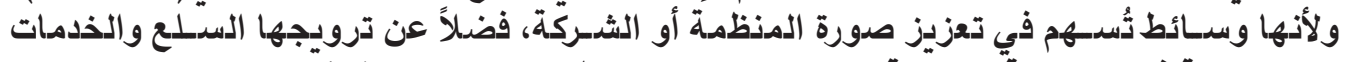

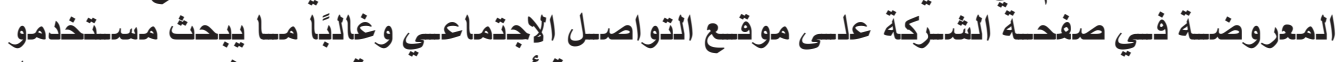

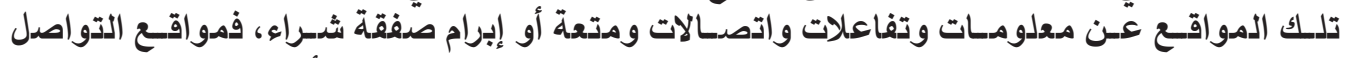

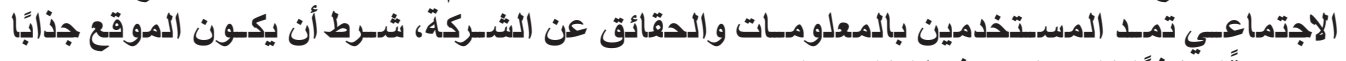

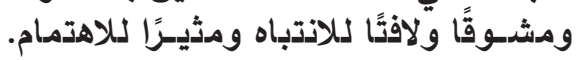

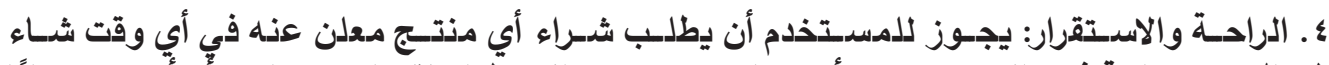

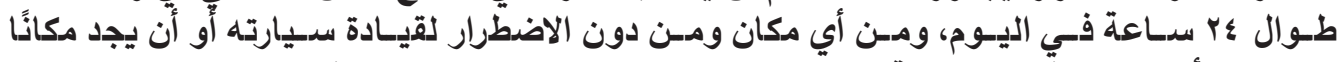

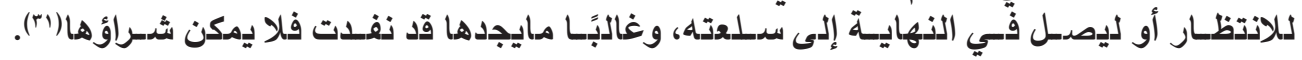

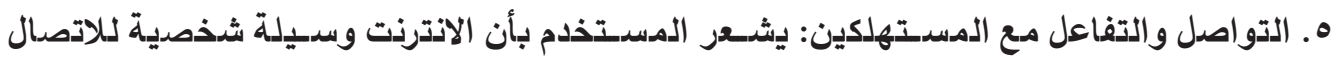

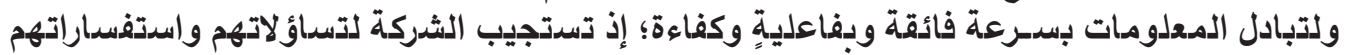

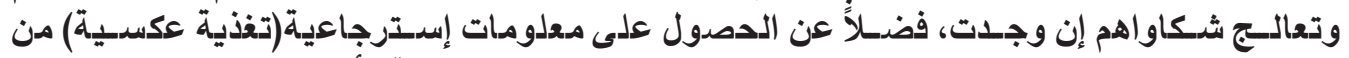

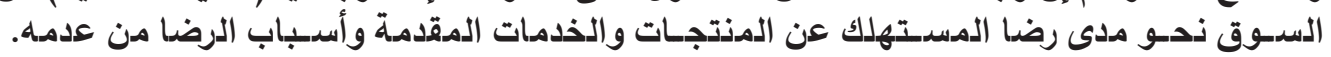

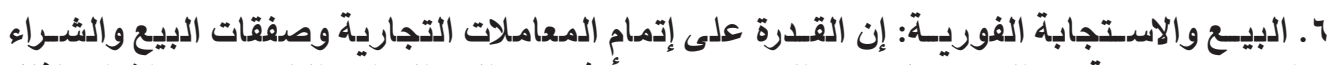

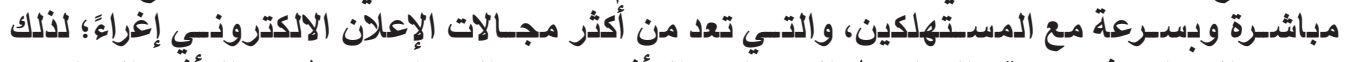

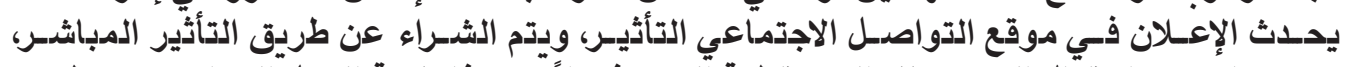

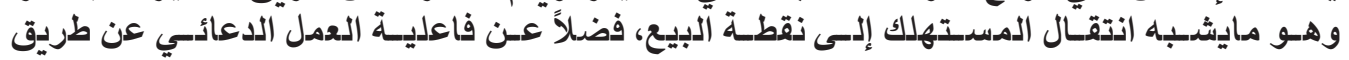

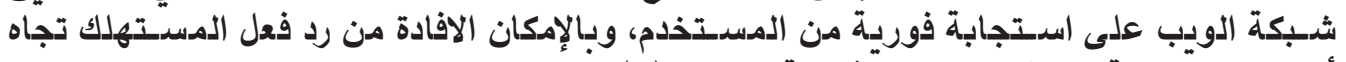

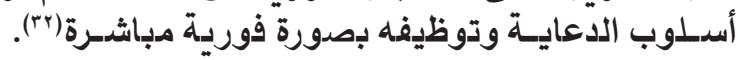

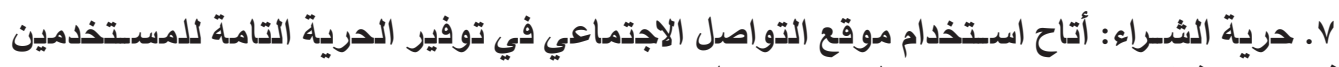

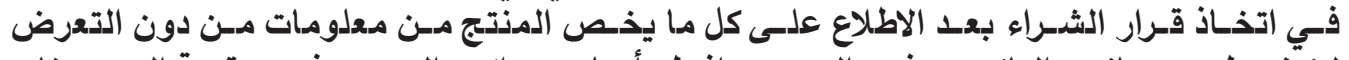

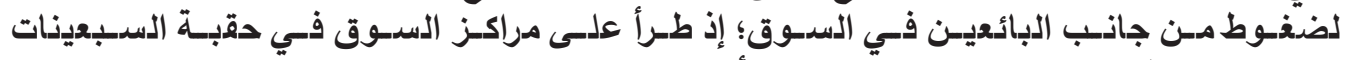

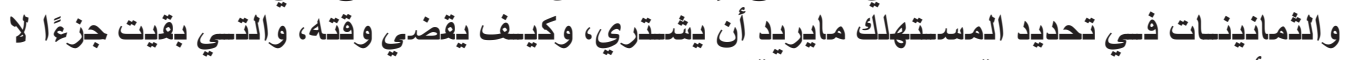

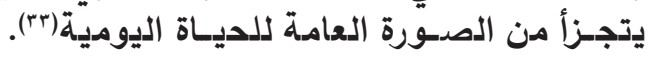

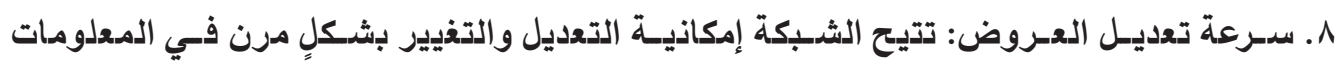
مجلة الباحث الإعلامي 


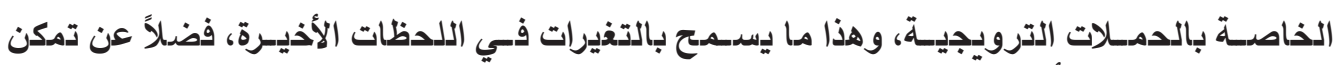

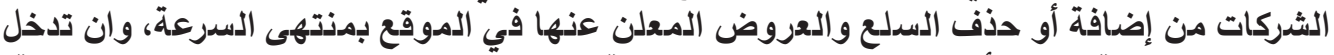

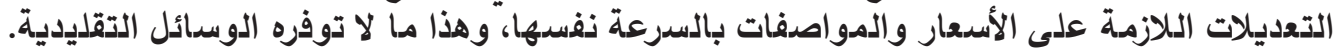

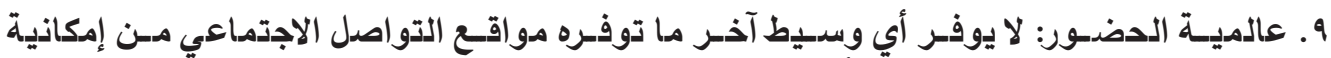

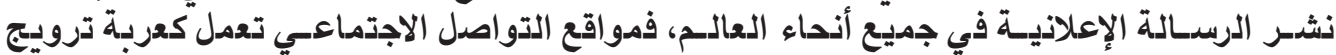

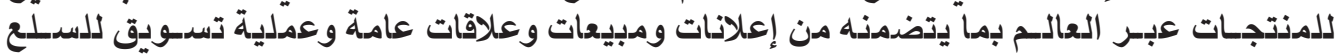

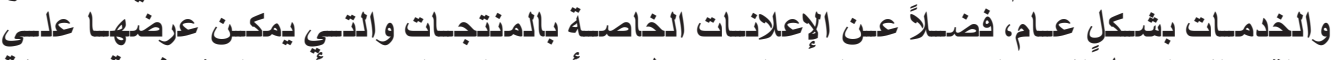

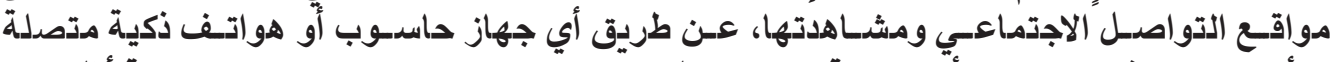

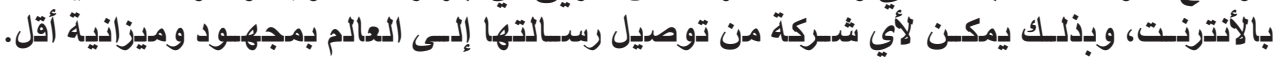

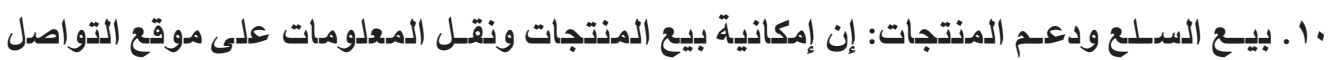

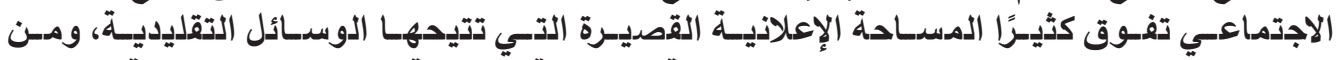

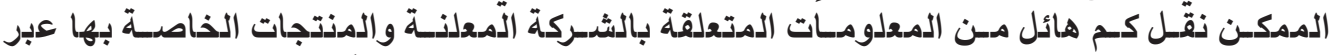

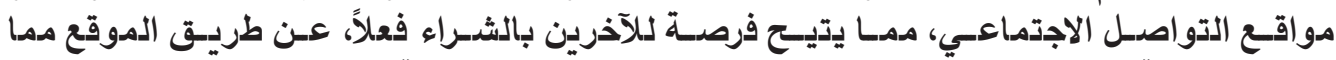

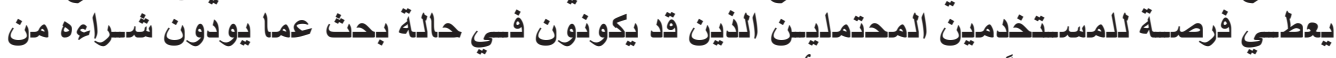

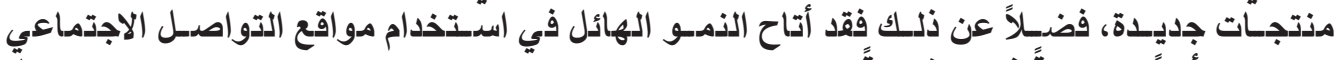

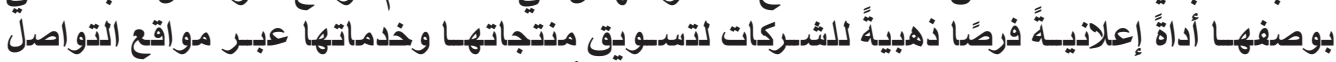

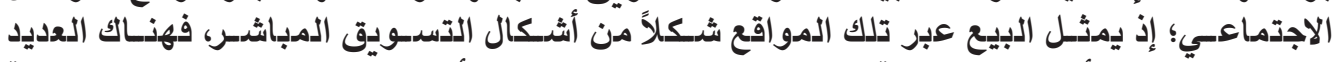

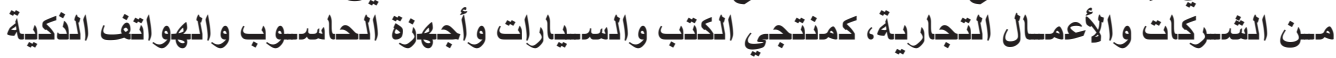

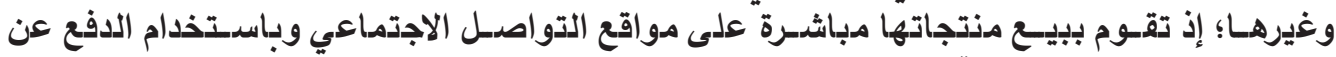

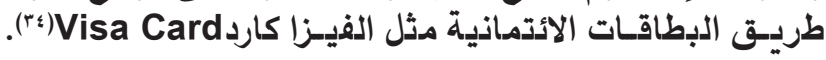

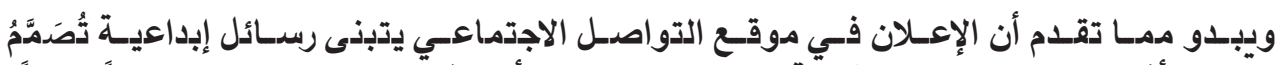

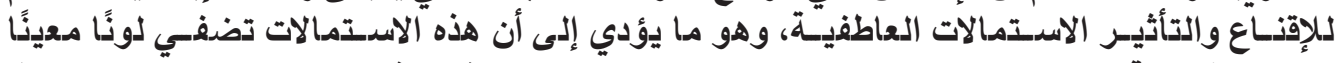

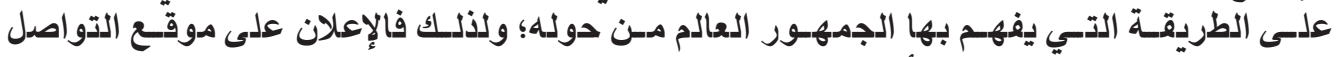

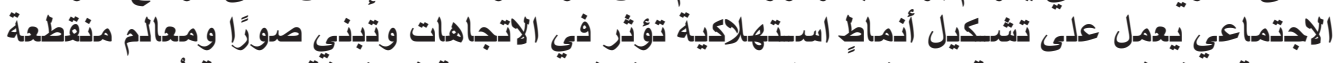

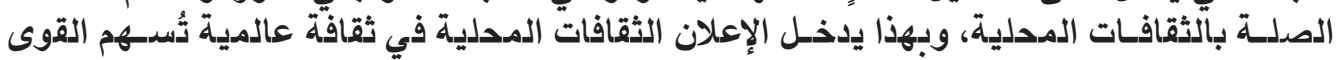

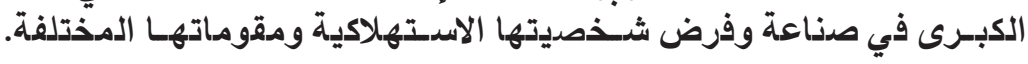

\section{الدراسة الميدانية}

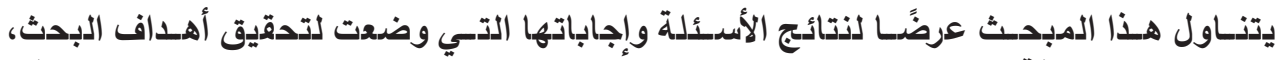

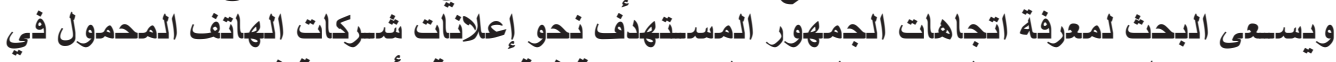

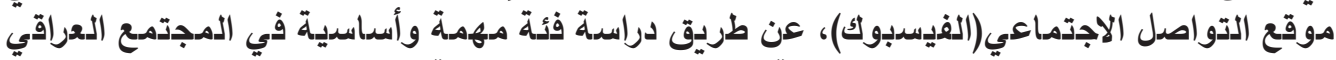

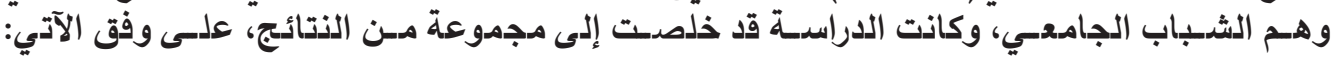

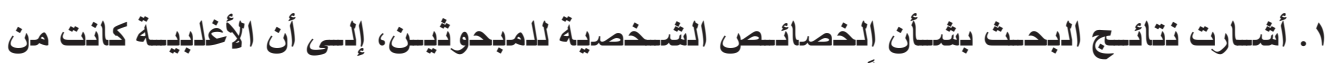

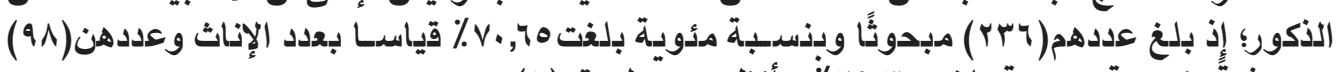

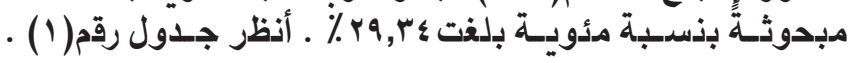




\section{جدول( (1) يوضح النوع الاجتماعي للعينة}

\begin{tabular}{|c|c|c|}
\hline النسبة المئوية & التكرار & العبارة \\
\hline $70 \cdot 65$ & 236 & ذكر \\
\hline $29 \cdot 34$ & 98 & أنثى \\
\hline $100 \%$ & 334 & المجموع \\
\hline
\end{tabular}

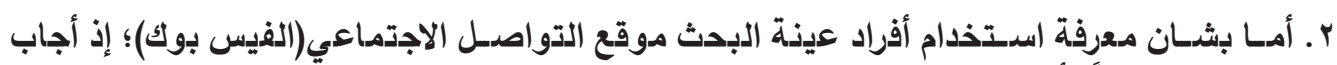

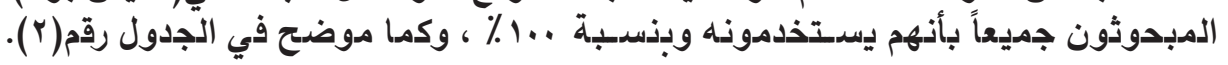
جدول(r) يوضح إجابات المبحوثين نحو اسـتخدام موقع (الفيسبوك)

\begin{tabular}{|c|c|c|}
\hline النسبة المئوية & التكرار & العبارات \\
\hline $100 \%$ & 334 & نعم \\
\hline$\longrightarrow$ & - & كلا \\
\hline $100 \%$ & 334 & المجموع \\
\hline
\end{tabular}

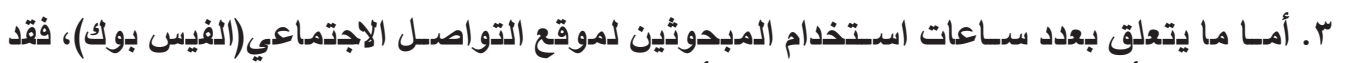

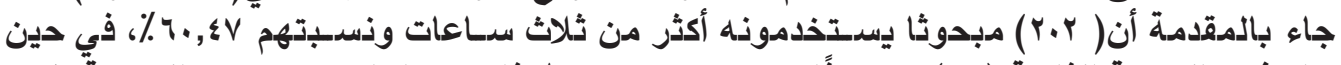

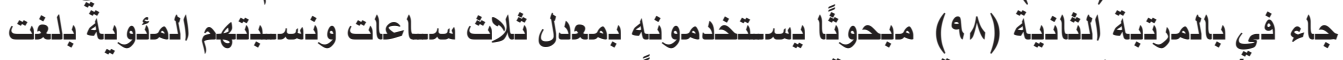

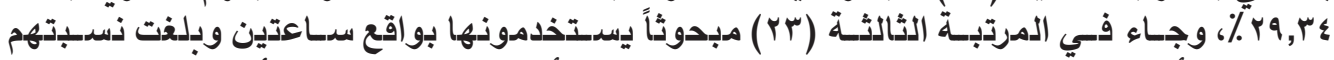

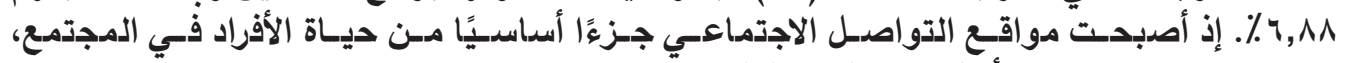

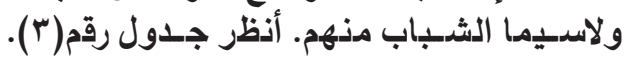

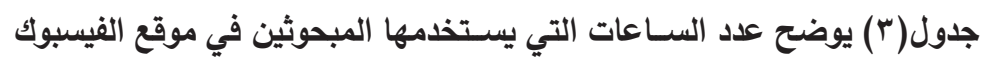

\begin{tabular}{|c|c|c|c|}
\hline النسبة المئوية & التكرار & العبارات & $ت$ \\
\hline 60,47 & 202 & أكثر من ثلاث ساعات & .1 \\
\hline 29.34 & 98 & ثلاث ساعات & .2 \\
\hline 6,88 & 23 & ساعتين & .3 \\
\hline 3,29 & 11 & ساعة واحدة & .4 \\
\hline $100 \%$ & 334 & & 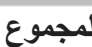 \\
\hline
\end{tabular}

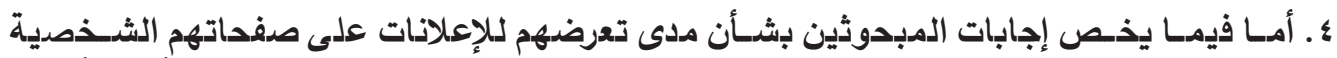

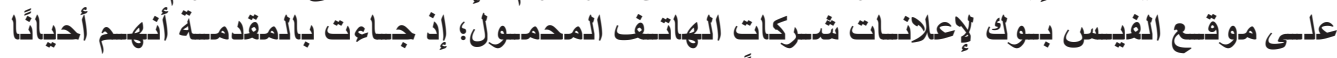

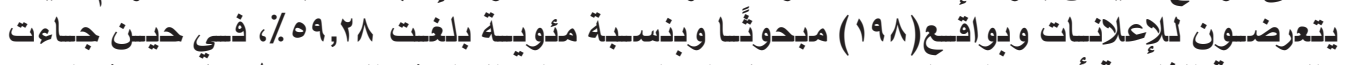

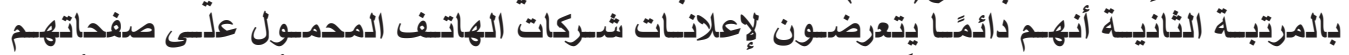

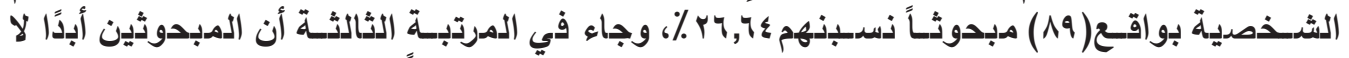

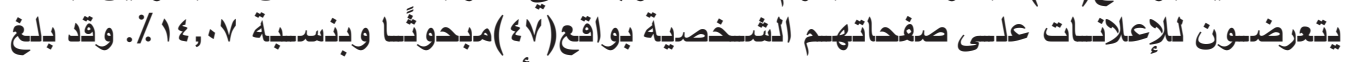

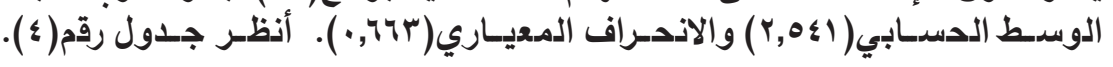

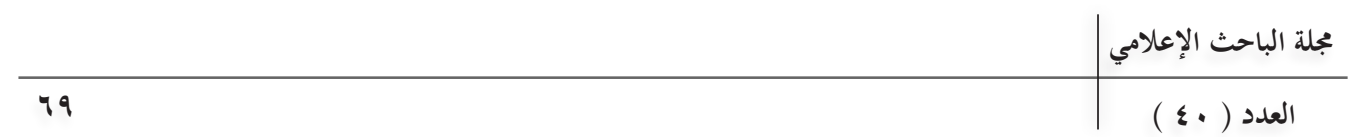


جدول(ع) يوضح إجابات المبحوثين لمدى التعرض للإعلانات التي تظهر على صفحتك في القيسـبوك

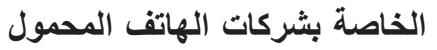

\begin{tabular}{|c|c|c|c|c|c|}
\hline الاتحراف المعياري & الوسط الحسابي & النسبة المئوية & التكرار & العبارات & ت \\
\hline \multirow{3}{*}{0.663} & \multirow{4}{*}{2.541} & Y4.7 & $\wedge q$ & دائماً & .1 \\
\hline & & $09, r \wedge$ & 191 & أحياناً &.$r$ \\
\hline & & $1 \leqslant 6 . V$ & $\leqslant V$ & أبداً &.$r$ \\
\hline & & $\% 1 \ldots$ & ع سץ & جموع & \\
\hline
\end{tabular}

هـ وفيمـا يتعلـق بخصائسص الإعلانـات علـى موقــع الفيسدبوك لشـركات الهاتـف المحمول،

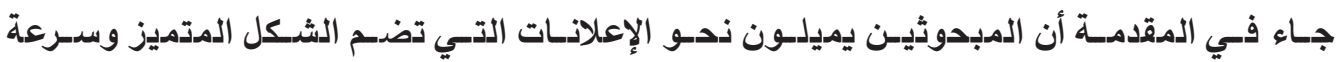

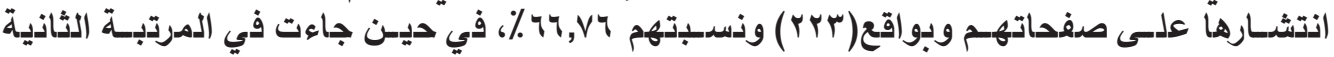

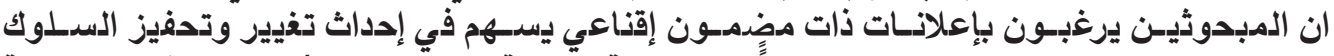

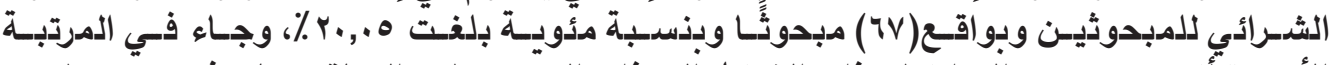

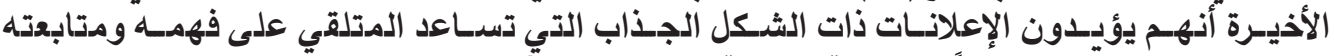

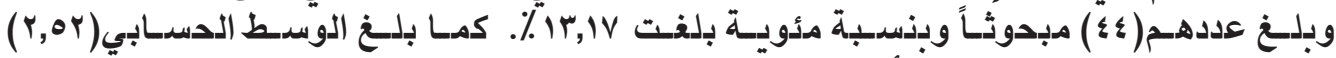

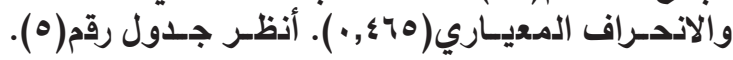

جدول(0) يوضح خصائص الاعلانات علم, موقع الفيسـبوك لثـركات الهاتف المحمول

\begin{tabular}{|c|c|c|c|c|c|}
\hline 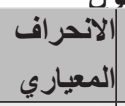 & 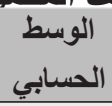 & المئوية & 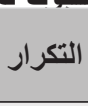 & 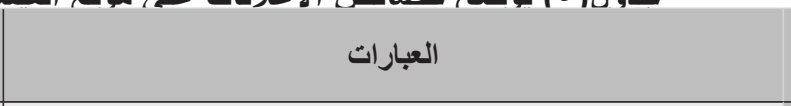 & $ت$ \\
\hline \multirow{4}{*}{0.465} & \multirow{4}{*}{2.52} & 66.76 & 223 & الثكل المتميز وسرعة انتشارها على صفحات المستخدمين & 1 \\
\hline & & 20.05 & 67 & 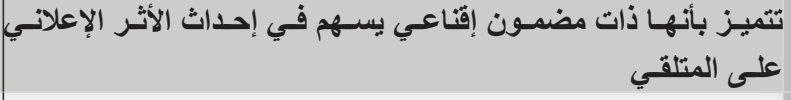 & 2 \\
\hline & & $13 \cdot 17$ & 44 & لها شكل إخراجي جذاب يساعد المتلقي على قراعته ومتابعته بسهولة & 3 \\
\hline & & $100 \%$ & 334 & المجوع & \\
\hline
\end{tabular}

צ. أشـارت نتائسج البحث فيمـا يخص أسدباب تفضيـل مشـاهدة الإعلانـات علـى صفحاتهـم

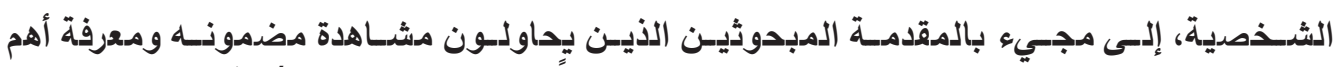

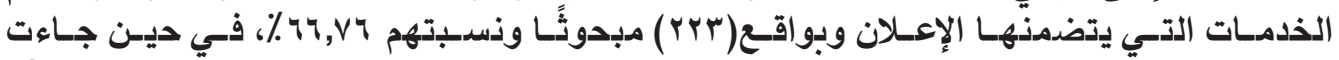

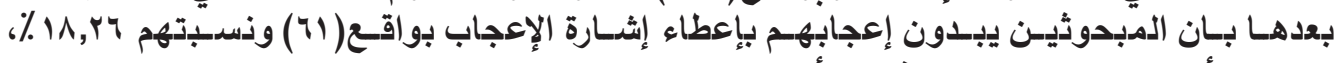

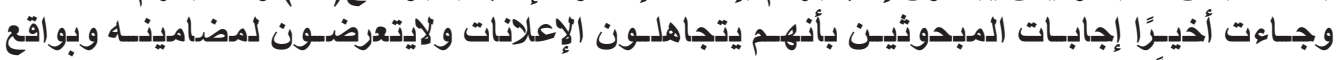

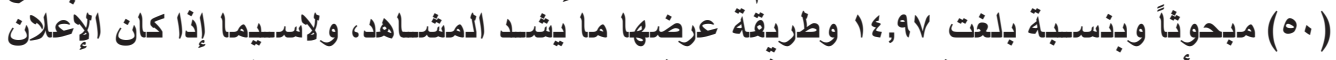

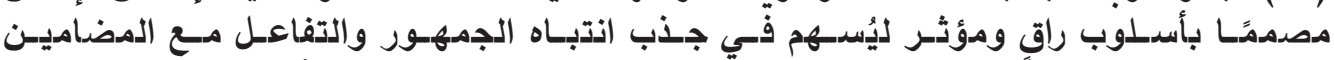

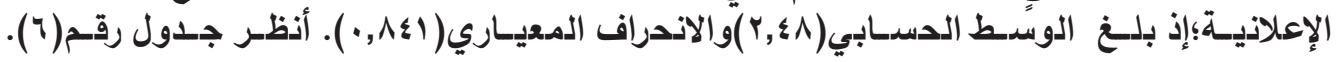

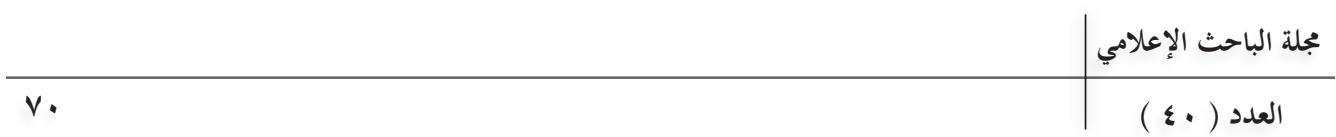




\begin{tabular}{|c|c|c|c|c|c|}
\hline الالمعياري & الكسابي & المئوية & 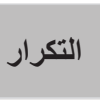 & 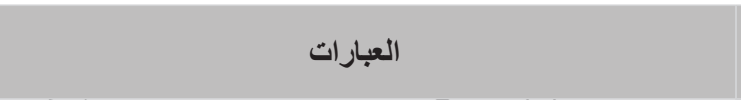 & $ت$ \\
\hline \multirow{4}{*}{0.841} & \multirow{4}{*}{2.48} & 66.76 & 223 & أحاول مشاهدة مضمونه و آلتعرف على أهم الخدمات التي يتضمنها & 1 \\
\hline & & $18 \cdot 26$ & 61 & أبدي إعجابي به عن طريق(Like) & 2 \\
\hline & & 14.97 & 50 & أتجاهله ولا أتعرض لمضمونه & 3 \\
\hline & & $100 \%$ & 334 & 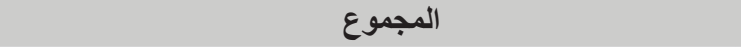 & \\
\hline
\end{tabular}

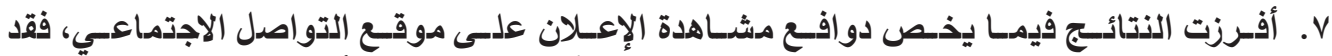

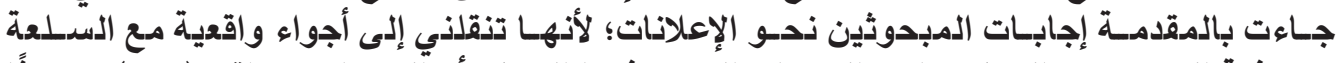

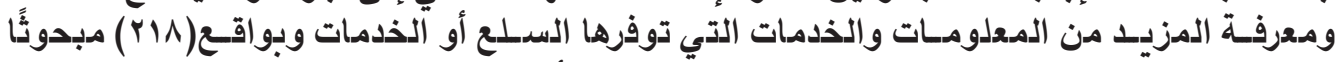
ونسـبتهم

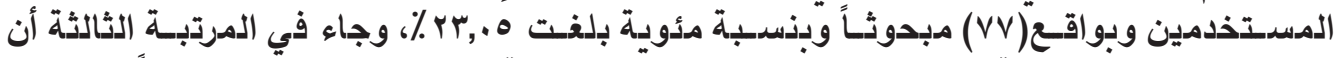

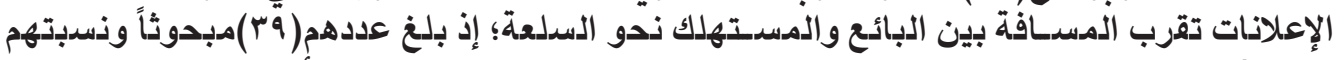

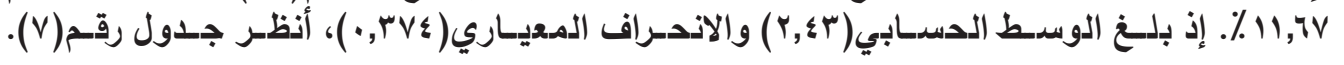

جدول(V) يوضح إجابات المبحوثين بخصوص دوافع مشـاهدة الإعلان على موقع(الفيسـوثك)

\begin{tabular}{|c|c|c|c|c|c|}
\hline الانحر اف & الحسابي & المئوية & 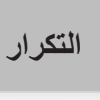 & 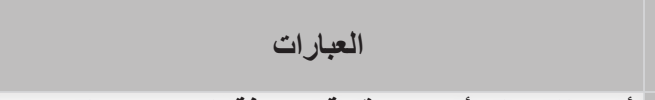 & $ت$ \\
\hline \multirow{4}{*}{0.374} & \multirow{4}{*}{2.43} & $65 \cdot 26$ & 218 & لأنه ينقلني إلى أجواء واقعية ومعرفة المزيد عن الذدمات & 1 \\
\hline & & 23.05 & 77 & يركز على الثكل لجذب انتباه المستخدمين & 2 \\
\hline & & 11.67 & 39 & يقرب المسافة بين البائع والمستهلك & 3 \\
\hline & & $100 \%$ & 334 & المجموع & \\
\hline
\end{tabular}

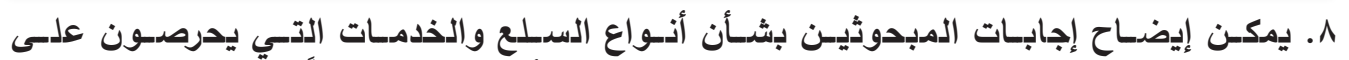

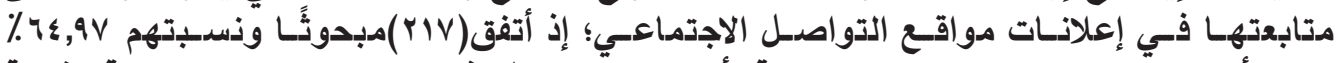

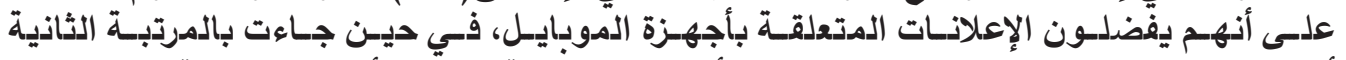

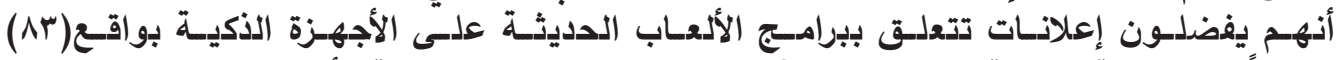

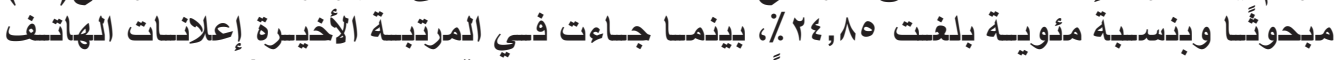

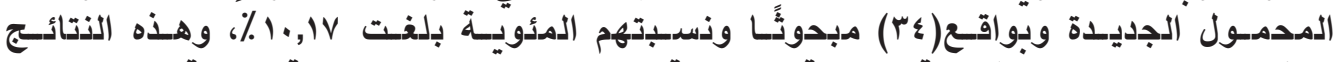

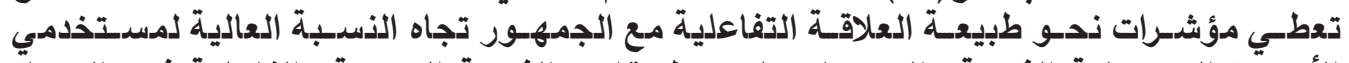

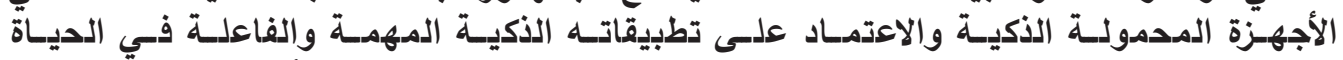

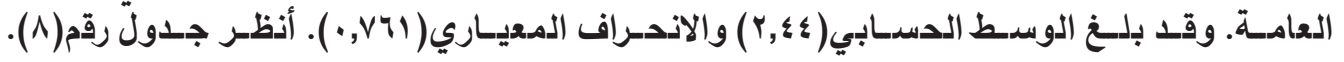

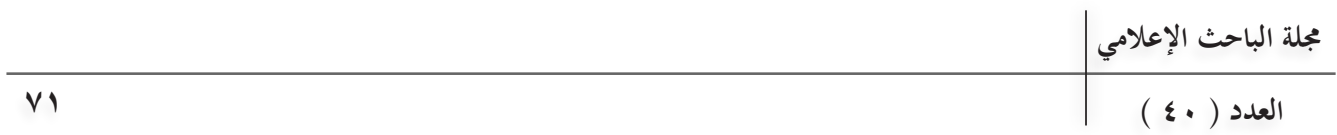


أ.م.د. محمد جياد زين الدين اتجاهات الشباب الجامعي نحو إعلانات شركات الهاتف المحمول

جدول(^)يوضــح إجابات المبحوثين بثـأن أنـواع المنتجات التي يحرصون على متابعتها في إعلانات موقع (الفيسبونك)

\begin{tabular}{|c|c|c|c|c|c|}
\hline الانحراف & الوسط الحسبي & المئوية & 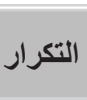 & 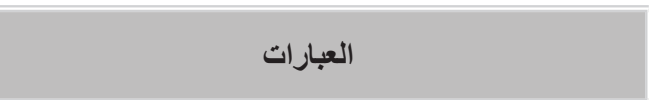 & $ت$ \\
\hline \multirow{4}{*}{0.761} & \multirow{4}{*}{2.44} & 64,97 & 217 & إعلانات تتعلق بأجهزة الموبايل & 1 \\
\hline & & 24,85 & 83 & إعلانـات تتعلق بيرامج الألعاب الدليثة على الأجهزة الذكية & 2 \\
\hline & & 10,17 & 34 & إعلانات الهاتف المحمول الجديدة & 3 \\
\hline & & $100 \%$ & 334 & المجمــوع & \\
\hline
\end{tabular}

و. أوضدـت نتائسج البحث بشـأن إجابـات المبحوثين فيما يخص ابرز العناصدر الإعلانية الأكثر تأثيرًا

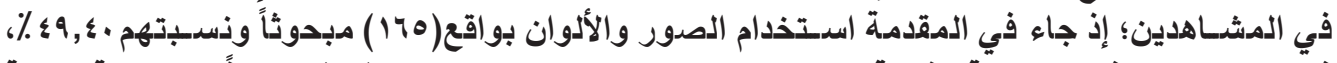

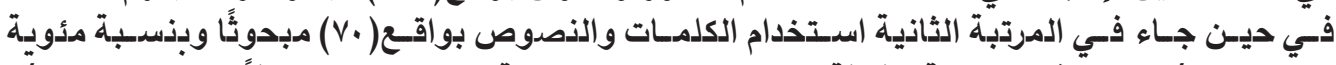

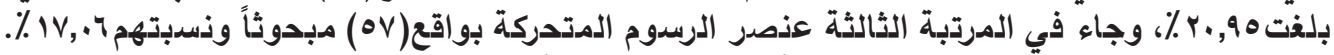

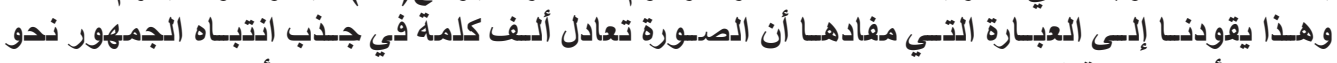

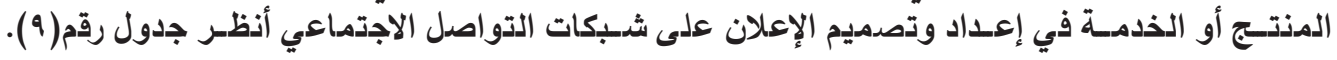
جدول(9) يوضح إجابات المبحوثين بخصوص ابرز العناصر الإعلانية تأثيراً على المستهلك في موقع (الفيسـبوك)

\begin{tabular}{|c|c|c|c|}
\hline النسبة المئوية & التكرار & العبارات & $ت$ \\
\hline $49 ، 40$ & 165 & الصور والألوان & .1 \\
\hline 20,95 & 70 & استخدام الكلمات والنصوص & .2 \\
\hline 17,06 & 57 & الرسوم المتحركة & .3 \\
\hline 12.57 & 42 & العنوان & .4 \\
\hline $100 \%$ & 334 & & المجموع \\
\hline
\end{tabular}

•ا ـ أوضحت نتائسج البحث بشـأن إجابـات المبحوثيـن فيمـا يخص السدلـع التسي يفضدونهـا

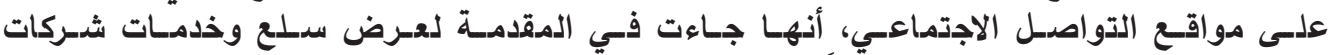

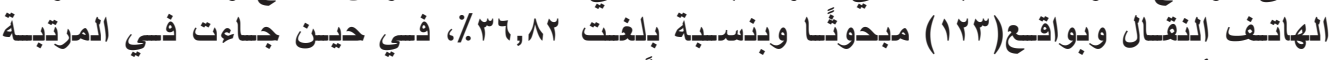

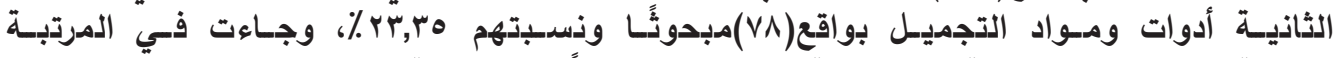

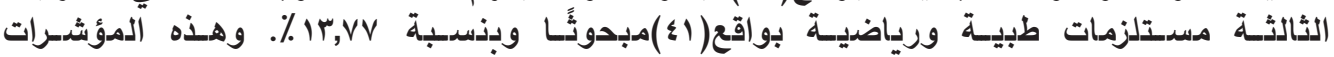

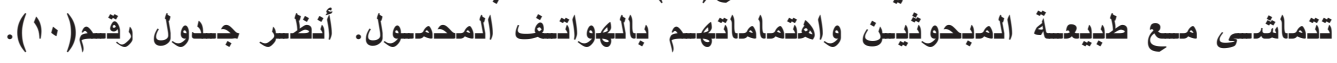
جدول( • 1) يوضـح إجابات المبحوثين بشـأن الســلع التي تفضل أن يعلن عنها في موقع (الفيسـبوك)

\begin{tabular}{|c|c|c|c|}
\hline النسبة المئوية & التكرار & العبارات & $ت$ \\
\hline $36 \cdot 82$ & 123 & سلع خدمات شركات الهاتف المحمول & 1 \\
\hline 23.35 & 78 & أدوات ومواد التجميل & 2 \\
\hline $12 \cdot 27$ & 41 & المواد الغذائية & 3 \\
\hline 13.77 & 46 & مستلزمات طبية ورياضية & 4 \\
\hline $10 \cdot 17$ & 34 & |أدوات كهربائية ومنزلية & 5 \\
\hline 3.59 & 12 & | الصحية والمنظفات & 6 \\
\hline $100 \%$ & 334 & & 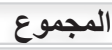 \\
\hline
\end{tabular}

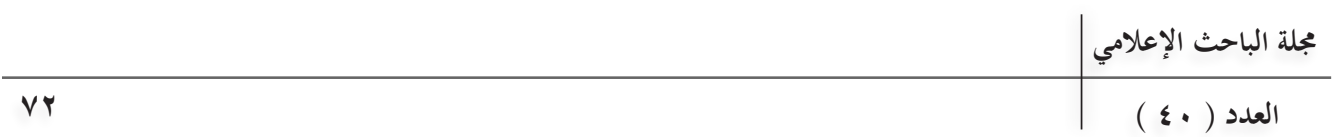




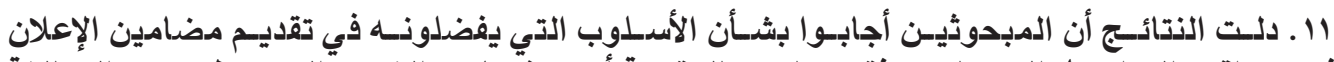

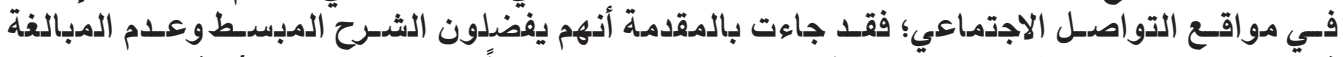

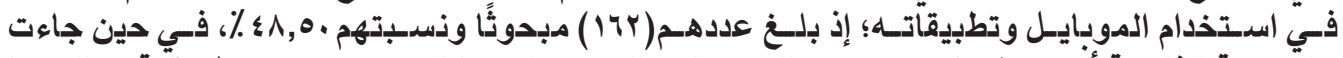

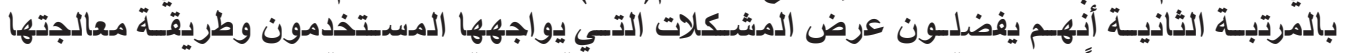

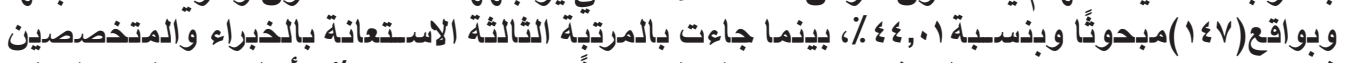

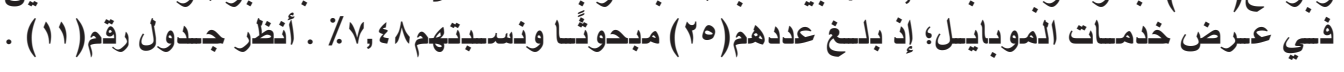

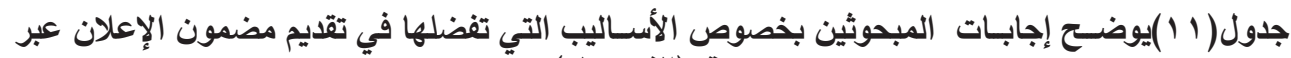
موقع (الفيسبوثك)

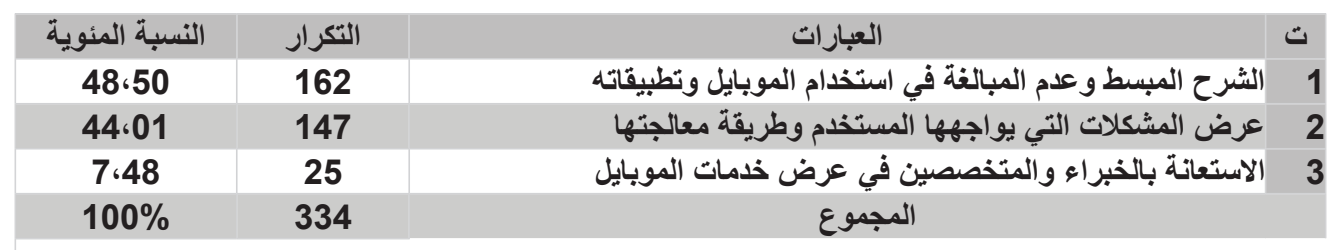

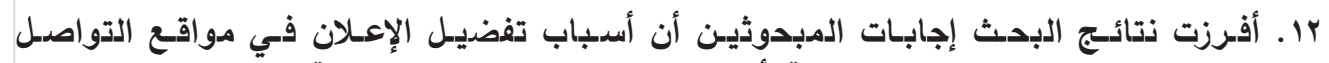

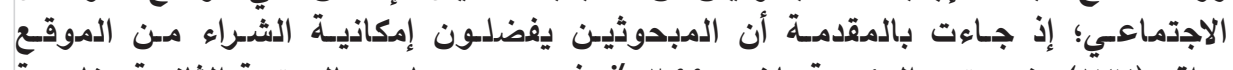

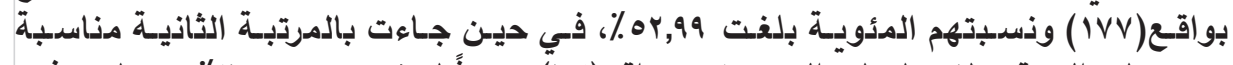

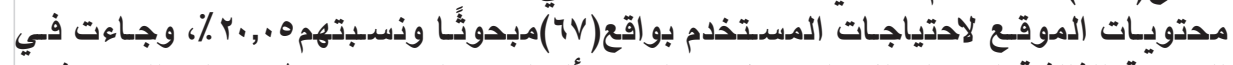

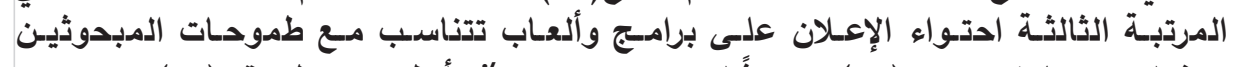

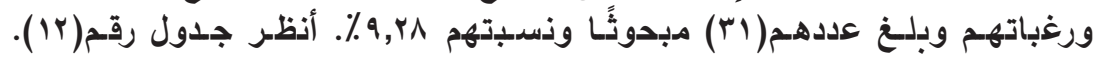

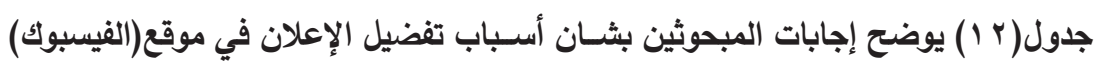

\begin{tabular}{|c|c|c|c|}
\hline النسبة المئوية & التكرار & العبارات & 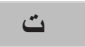 \\
\hline $52 ، 99$ & 177 & 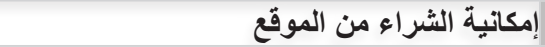 & 1 \\
\hline 20.05 & 67 & مناسبة محتويات الموقع لاحتياجات المستخدمين & 2 \\
\hline 9.28 & 31 & احتو اؤه على البرامج والألعاب & 3 \\
\hline 6.88 & 23 & سهولة الاستخدام & 4 \\
\hline 4,79 & 16 & سرعة التحميل & 5 \\
\hline 3.29 & 11 & تقايم الكويونات والمحفزات & 6 \\
\hline 2,69 & 9 & |تحديث الموقع باستمرار & 7 \\
\hline $100 \%$ & 334 & & المجمو \\
\hline
\end{tabular}

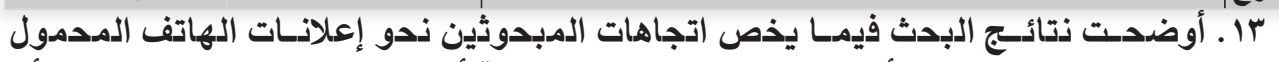

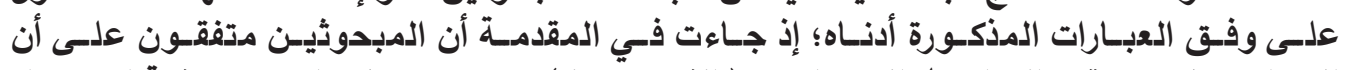

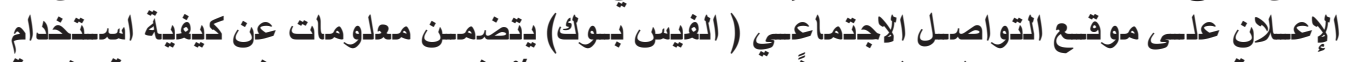

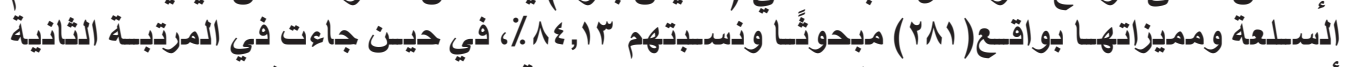

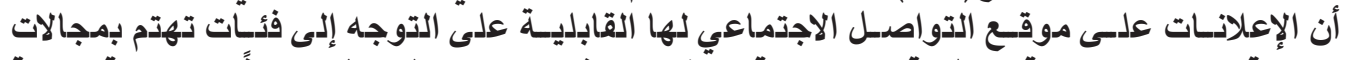

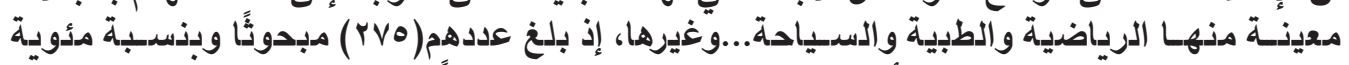

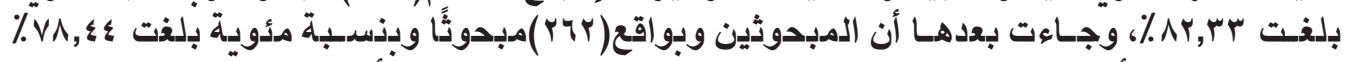

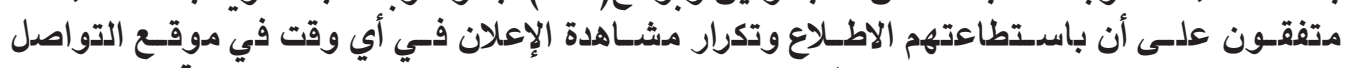

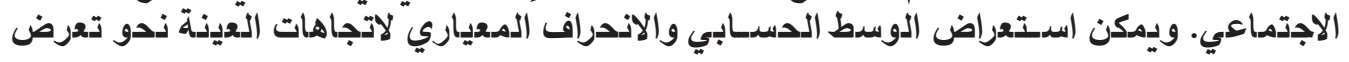


العينــة لإعلانات شـركات الهاتـف المحمول في موقـع التواصدل الاجتماعي. أنظر جـدول رقم(سات ). جدول(ب ا) يوضـح اتجاهات المبحوثين بثـأن العبارات التي تخص الإعلانات في موقع التواصل الاجتماعي(الفيسـبوك)

\begin{tabular}{|c|c|c|c|c|c|c|c|c|}
\hline 20 & $=:$ & 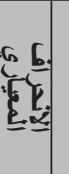 & $\begin{array}{l}a \\
\underline{E} \\
\underline{E} \\
\underline{E}\end{array}$ & 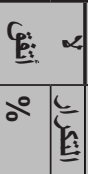 & $\circ$ & 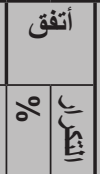 & 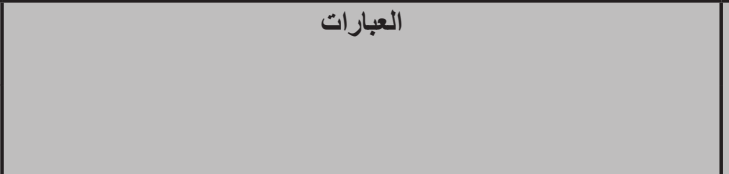 & $\ddot{ت}$ \\
\hline 형 & $\underset{\omega}{\omega}$ & 잉 & No & $\begin{array}{c}\vec{\omega} \\
\vec{v}\end{array}$ & \begin{tabular}{l|l}
$\infty$ & \\
के & है \\
\end{tabular} & 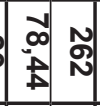 & ستطيع الاطلاع وتكرار مشاهدة الإعلان في أي وقت. & 1 \\
\hline$\vec{\circ}$ & $\underset{\omega}{\omega}$ & 일 & $\stackrel{\sim}{\sim}$ & 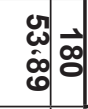 & $\hat{A}$ & 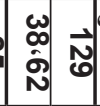 & 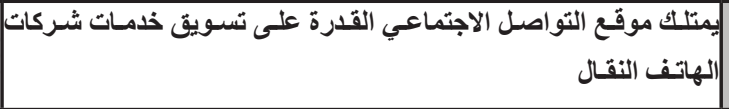 & 2 \\
\hline$\vec{\circ}$ & $\underset{\omega}{\omega}$ & 일 & vำ & $\begin{array}{l}\vec{\sigma} \\
\hat{े} \\
\text { के }\end{array}$ & ô. & 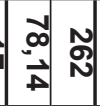 & كلانات موقع التواصل الاجتماعي بالمواثيق الأخلاقية. & 3 \\
\hline$\vec{\circ}$ & $\underset{\omega}{\oplus}$ & 일 & $\stackrel{\text { Na }}{9}$ & $\begin{array}{ll}\infty \\
0 \\
\infty\end{array}$ & \begin{tabular}{|l|l|}
$\vec{\infty}$ & 0 \\
$\hat{\sigma}$ & 0
\end{tabular} & 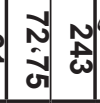 & 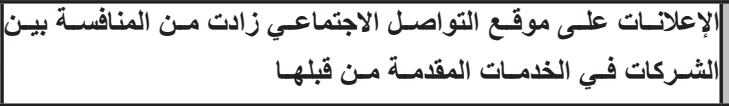 & 4 \\
\hline$\vec{\circ}$ & $\underset{\omega}{\omega}$ & : & \begin{tabular}{c}
$N$ \\
\hdashline \\
\hdashline
\end{tabular} & $\left.\begin{array}{c}\omega \\
\omega \\
\dot{\omega} \\
\omega \\
\omega\end{array}\right]$ & $\begin{array}{c}\omega \\
\hat{o} \\
\hat{o}\end{array}$ & Nָ & 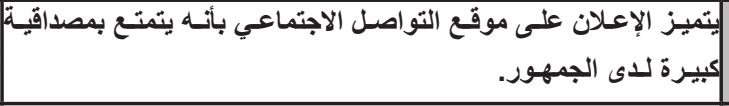 & 5 \\
\hline 형 & $\underset{\omega}{\omega}$ & जै & $\stackrel{n}{\dot{P}}$ & 岱 & No & $\overrightarrow{\text { जो }}$ & 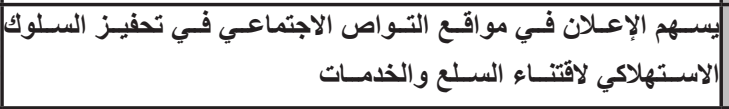 & 6 \\
\hline 형 & $\underset{\omega}{\omega}$ & 일 & กั & $\begin{array}{l}\vec{\omega} \\
\hat{\oplus}\end{array}$ & & 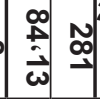 & 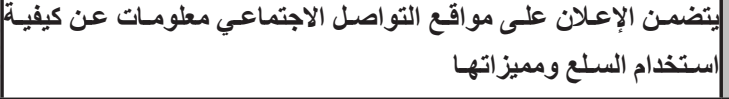 & 7 \\
\hline $\overrightarrow{8}$ & $\underset{\omega}{\omega}$ & 옥 & $\stackrel{\sim}{\mathfrak{\omega}}$ & N & \begin{tabular}{|l|l|l} 
& \\
$\infty$ & 1 \\
$\infty$ & 4 \\
$\infty$
\end{tabular} & 잉 : & 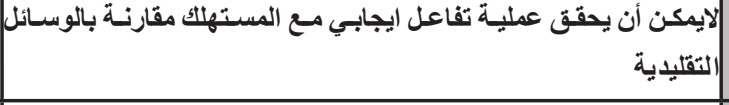 & 8 \\
\hline $\overrightarrow{8}$ & $\begin{array}{c}\omega \\
\omega \\
\phi\end{array}$ & $\begin{array}{l}\text { O } \\
\text { Aे }\end{array}$ & $\begin{array}{c}N \\
\text { o } \\
\text { N }\end{array}$ & $\overrightarrow{\hat{े}} \overrightarrow{0}$ & & $\begin{array}{c}\stackrel{0}{\omega} \\
\tilde{\omega} \\
\omega\end{array}$ & 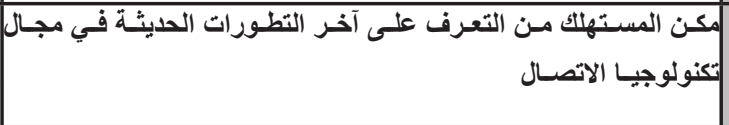 & 9 \\
\hline 형 & $\underset{\omega}{\omega}$ & 열 & $\stackrel{n}{n}$ & $\hat{\vec{N}}$ & $\overrightarrow{\hat{\theta}} 0$ & 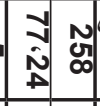 & 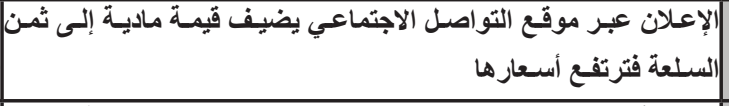 & 10 \\
\hline 형 & $\underset{\omega}{\omega}$ & $\begin{array}{c}\text { cे } \\
\text { जे } \\
\end{array}$ & ํ. & cin & 1 & \begin{tabular}{ll|}
0 \\
0 \\
0
\end{tabular} & ليتمتع بأسلوب جذاب وشيق في تحريز مضمون رسالته الإعلانية & 11 \\
\hline $\overrightarrow{8}$ & $\underset{\omega}{\omega}$ & 仓े & กั & $\stackrel{\omega}{\omega} \underset{\omega}{\omega}$ & $\begin{array}{lll}\infty & \\
\text { के } & \text { है } & 0 \\
\end{array}$ & $\left.\mid \begin{array}{cc}0 \\
0 \\
0 \\
0 \\
0\end{array}\right]$ & 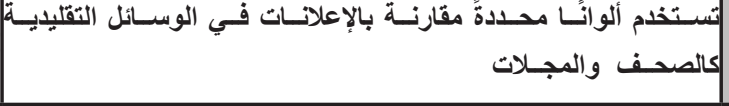 & 12 \\
\hline$\vec{\circ}$ & $\underset{\omega}{\omega}$ & 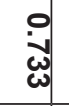 & $\stackrel{\sim}{\omega}$ & $\begin{array}{c}\text { No } \\
0 \\
0 \\
0\end{array}$ & \begin{tabular}{l|l}
0 & \\
0 & 0 \\
0 & 0 \\
$\infty$ & $c$ \\
\end{tabular} & 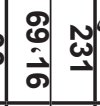 & 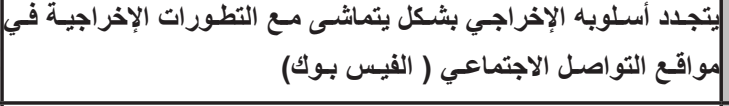 & 13 \\
\hline 형 & $\underset{\omega}{\omega}$ & $\stackrel{0}{ \pm}$ & $\stackrel{N}{\cdots}$ & $\begin{array}{c}\overrightarrow{0} \\
\text { ô } \\
\text { ô }\end{array}$ & $\vec{\Delta}$ & $\underset{\substack{\omega \\
\omega}}{N}$ ज & 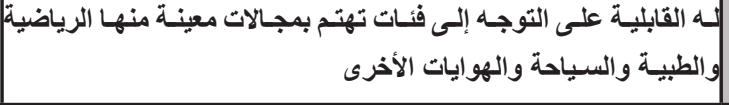 & 14 \\
\hline
\end{tabular}




\section{النتائج العامة}

في نهاية البحث توصل الباحث إلى عدد من النتائج العلمية، التي يمكن صياغتها على وفق الآتي:

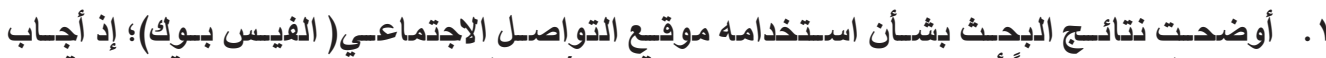

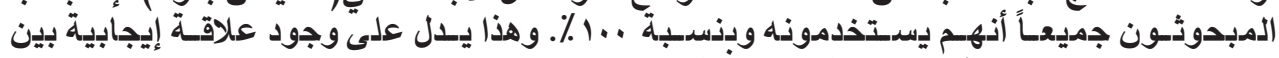

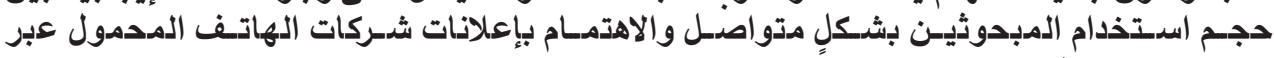
مواقـع التواصـل الاجتماعي.

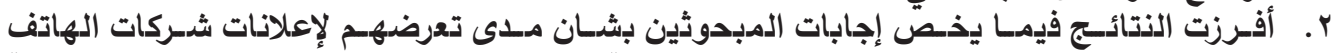

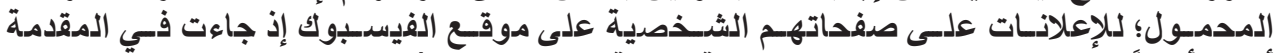

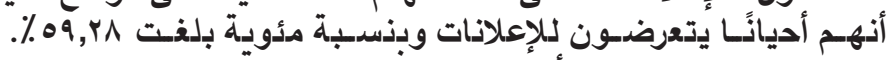

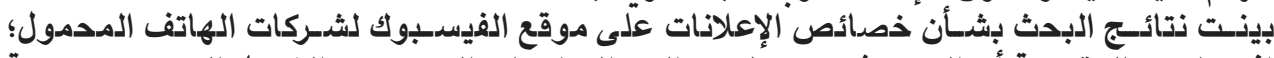

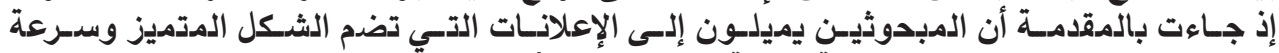

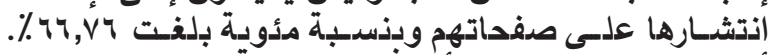

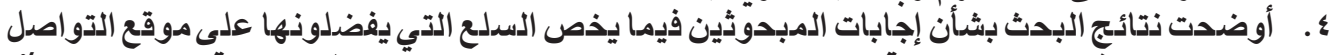

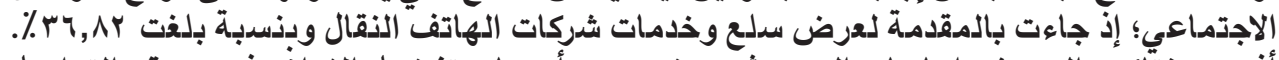

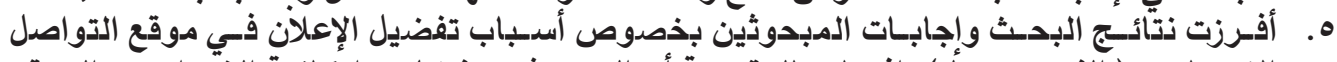

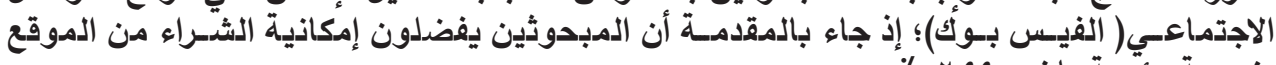

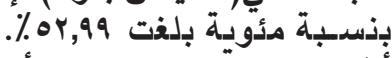

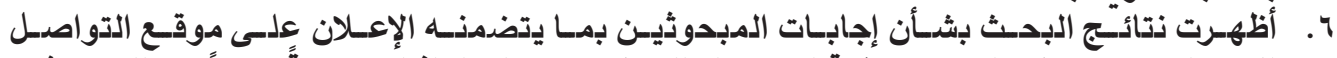

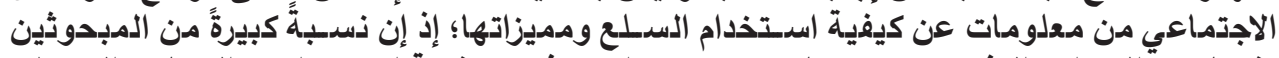

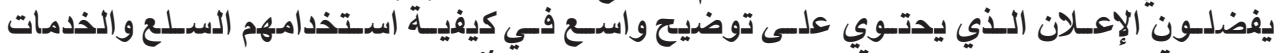

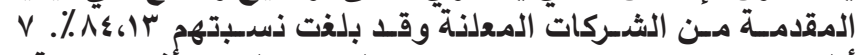

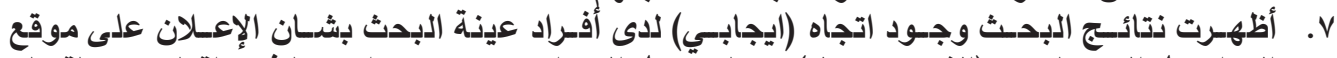

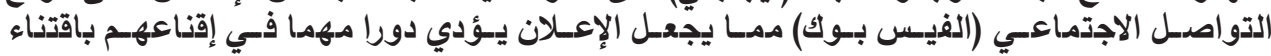
السـلع والخدمات المعلـن عنها.

التوصيات

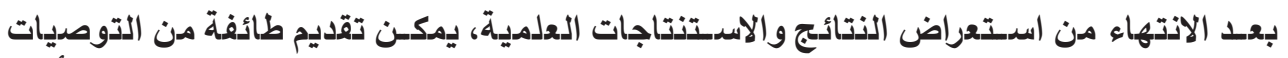

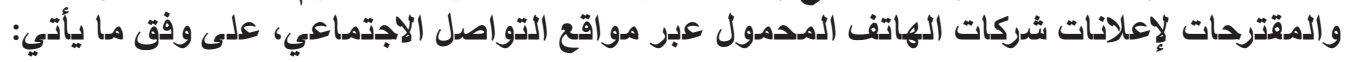

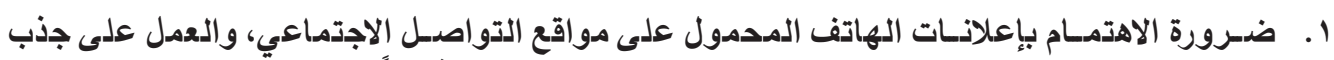

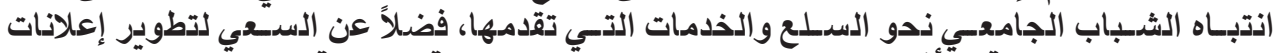

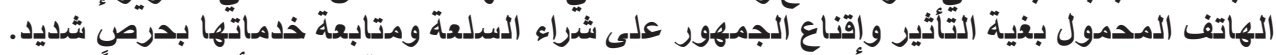

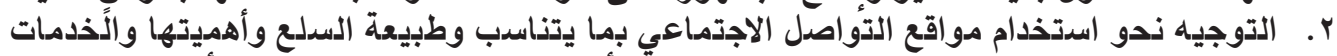

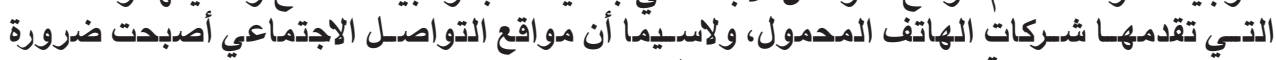

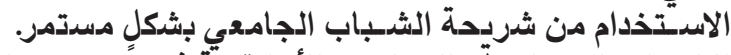

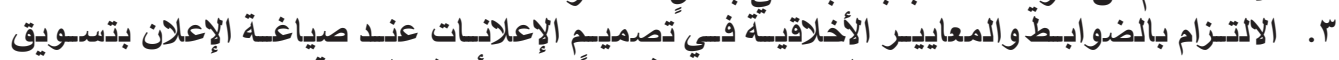

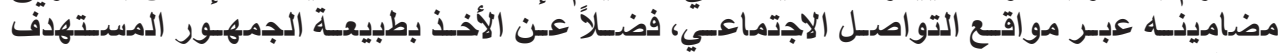

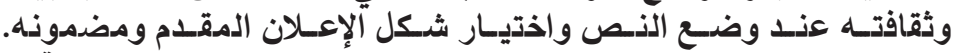

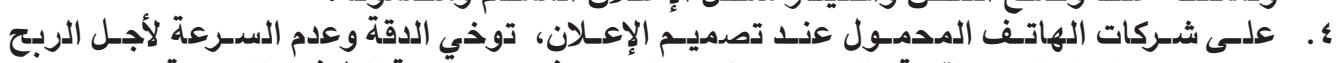

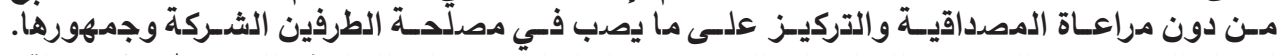

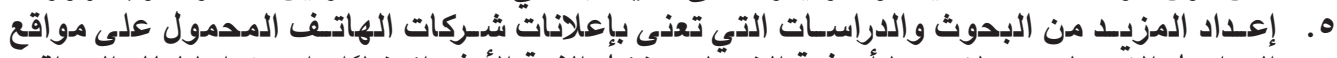

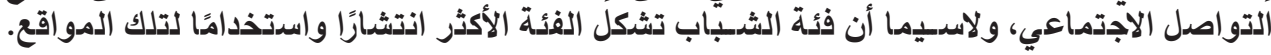




\section{هوامش ومصادر البحث}

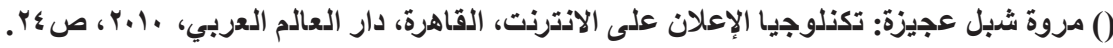

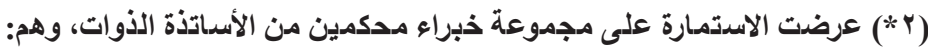

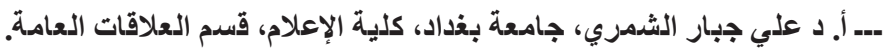

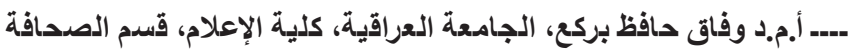
-..-. أ.م.د عبدالقادر صالح معروف، الجامعة العراقية، كلية الإعلام، قسم الصحافة الإذاعية والتدلفزيونية

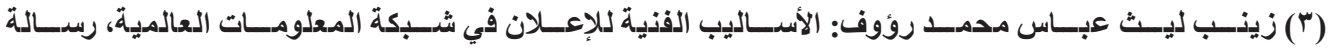

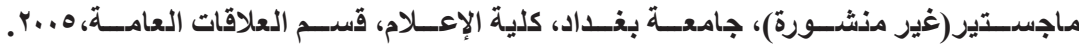

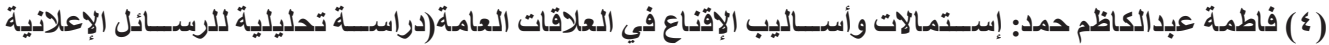

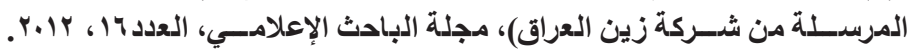

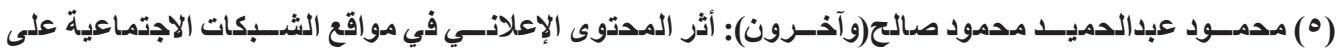

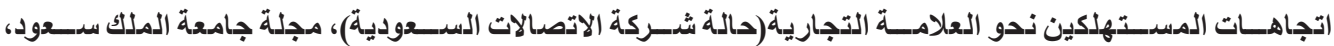

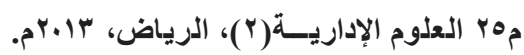

(7) Hyejin Bang \& Wei - Na Lee: Consumer Response to Ads in Social Network Sites; An Exploration into the Role of Ad Location and Path, Paper Presented at the annual meeting of the Association for Education in Journalism and Mass Communication, Renaissance Hotel, Washington DC, r.lr.

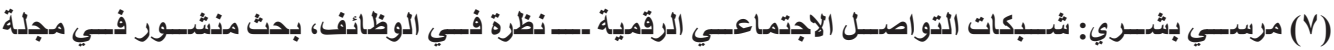

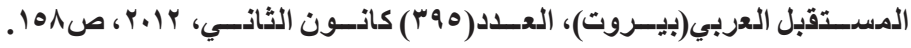

Mir, I. \& Zaheer, A. Verification of Social Impact Theory Claims in Social Media $(\wedge)$

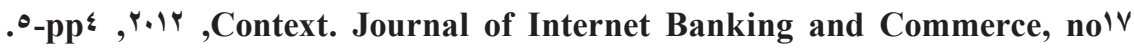

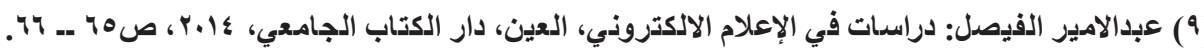

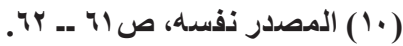

()"l Pronin, E. \& Gilovich, T.D., \& Ross, L. Objectivity in the eye of the beholder: Divergent perceptions of bias in self versus others. Psychological Review, no r.. \& , 11 . p, VNı.

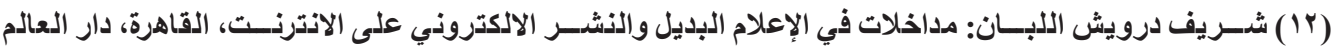

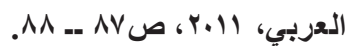

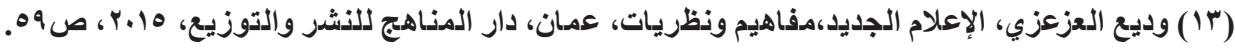

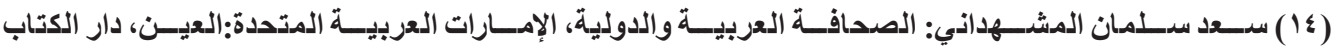

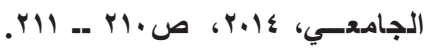

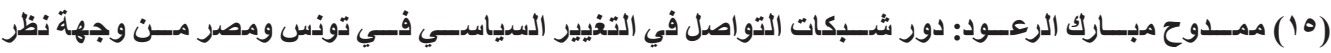

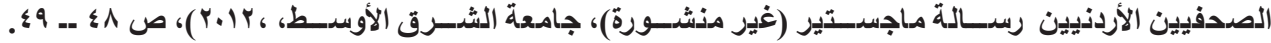

(') Cha, M., Kwak, H., Rodriguez, P,Ahn, Y.-Y. \& Moon, S. I tube, you tube, everybody tubes: analyzing the world's largest user generated content video system. Paper presented

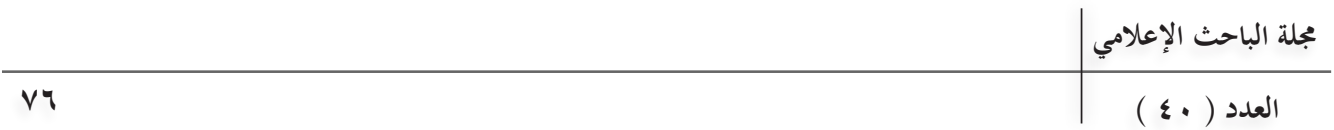


at the Proceedings of the $\mathrm{V}_{\text {th }}$ CMSIGCOMMConference on Internet measurement, San Diego, CA, October, r..V, pp; $r \varepsilon_{-} r$ r.

(IV) جمـال عبد العزيز الثـرهان: الوســائل التعليمية ومسدـتجدات تكذولوجيــا التعليــ، طץ، الرياض، مطابع

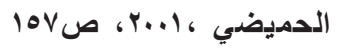

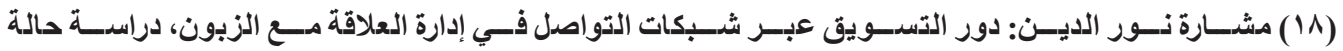

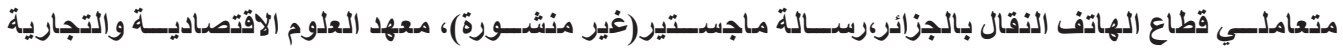

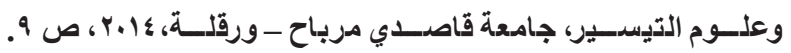

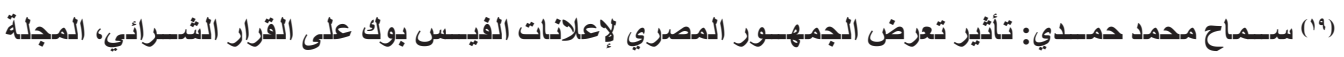

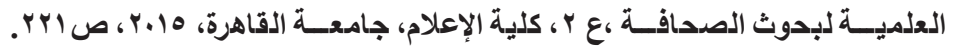

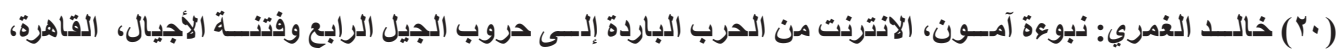

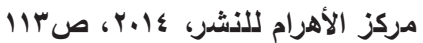

(r) Pronin, E., Lin, D. Y. \& Ross, L. The bias blind spot: Perceptions of bias in self versus

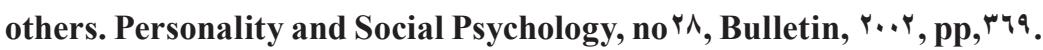

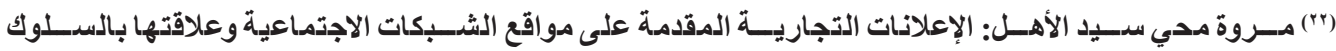

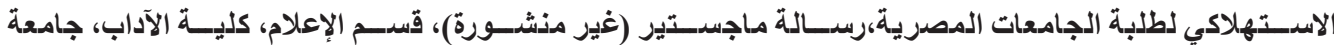

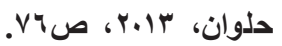

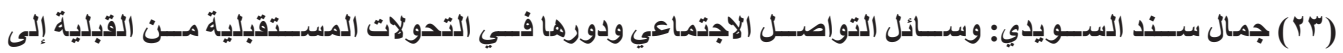

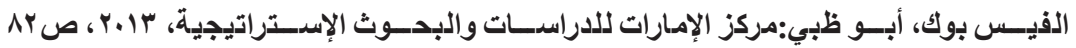

r६) ) Solis, B. (ed), Engage: The Complete Guide for Brands and Businesses to Build, Cultivate, and Measure Success in the New Web, 'st edn, John Wiley \& Sons, New York. $r+11, p$ |r.

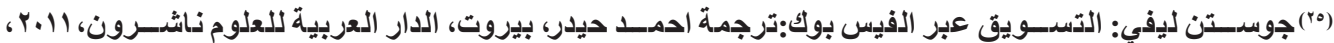
(119.

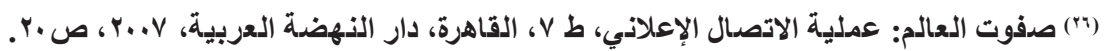

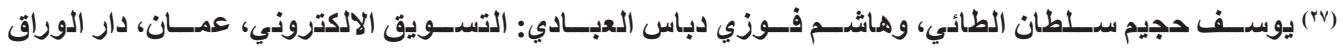

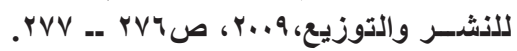

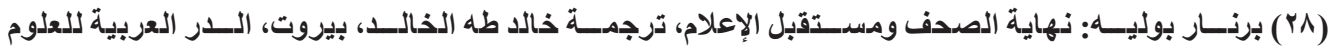

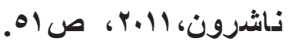
( ( ${ }^{\natural}$ ANAGNOSTOPOULOS, A.,KUMAR, R., AND MAHDIAN, M. Influence and correlation in social networks. In Proceedings of the 1 th Internal Conference on Knowledge Discover \& Data Mining. ACM Press, NewYork, NY, USA, ץ..^, pp .^_V

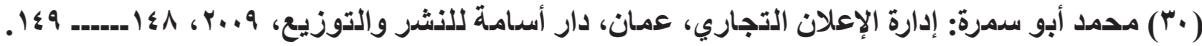

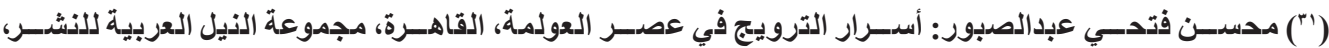
.AV ص r...l

) ${ }^{r}$ (Jansen, B.J., Zhang, M.M., Sobel, K., \& Chowdury, A. The commercial impact of

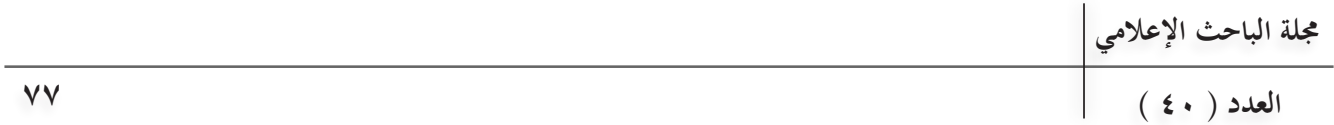


social mediating technologies: micro-blogging as online word of mouth branding. $\mathrm{CHI}$ ', 9 Proceedings of the $r V$ th International Conference Extended Abstracts on Human Factors in Computing Systems, Boston, MA, April $q_{-} \&$, Association for Computing Machinery (ACM), New York, NY, ץ..q, p, r^.

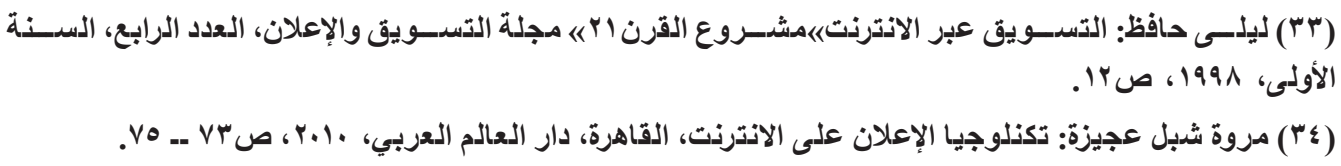

\section{Margins and Research Sources}

( ) Marwa shibl Ojaiza: Internet Advertising Technology, Cairo, AL- ALAM AL-ARABI Press, $r \cdot 1 \cdot, p^{r} \varepsilon$.

( $r)$ The from was presented to a panel of experts professors and They are:

-- prof.D. Ali Jabbar AL- Shammari, Baghdad Univwrsity, Media College, Public Relations, department.

-- Wifak Hafiz Burgie, Al-IRaqia University, Media College, Journalzim department.

-- prof Ass, stant,D, Abdul Al-kader salih Marouf, AL- IRaqia University, Media College, Radio and T.V jornal; zm department.

( $\left.{ }^{\Psi}\right)$ Zainab Laith Abbas Mohammed Rawof: Techical Methods of Advertising in the world wide web, (not published), Master research, Baghdad University, Media college public Relation department, r... .

(\&) Fatima Abdul Kazim Hamad: Advocacy and persuasion in Public Relations(Analaytical study of advertising messages sent by zain Iraq, AL-Bahith AL-ELami Magazine, r. ${ }^{\prime}$.

( $)$ Mahmoud Abdulhamid Mahmoud Salih(and Others): The impact of old contcatin Social networking Sites on Consumer attitudes towards the brand(The Case of STS)king Saud University Magazine roM, administrationScience( $r$ ), Riyadh, r.1r.

( 7 ) Hyejin Bang \& Wei - Na Lee: Consumer Response to Ads in Social Network Sites; An Exploration into the Role of Ad Location and Path, Paper Presented at the annual meeting of the Association for Education in Journalism and Mass Communication, Renaissance Hotel, Washington DC, r.lr.

( $\vee$ ) Murs: Bishri: Digital Social networks- glances to Careers, Published research in ALMustakbal ALARabi Magazine(Beirut): $r q 0$ January, r.|r, p 10^.

(^) Mir, I. \& Zaheer, A. Verification of Social Impact Theory Claims in Social Media Context. Journal of Internet Banking and Commerce, nor.lr, iv, pp ${ }^{\bullet_{-}}$.

(१) Abdul Amir ALfaisal: studies in Electronic Media, ALAin, ALkitab ALjamie: Press,

\begin{tabular}{l|c} 
& مجلة الباحث الإعلامي \\
\hline V^ & العدد ( • ع )
\end{tabular}


Y.1ะ, pp $74-70$.

(1.) The Samesource pp ir-7l.

('i) Pronin, E. \& Gilovich, T.D., \& Ross, L. Objectivity in the eye of the beholder: Divergent perceptions of bias in self versus others. Psychological Review, no r.. \&, 11 . p, $\vee \wedge 1$

(ir) Sharif DArwish ALLABBan: Interventions in alternative Media and online Publishing, Cairro:: ALALAM ALarabi, Press, r.ll, pp $p^{\wedge \wedge} \wedge$.

(1 $\left.{ }^{r}\right)$ Wadia ALboizzi: New Media, Concepts and theories, AMMan, ALmanahij press and distribution, r.10, p ${ }^{\circ}$.

(1६) Saad Salman ALmashhadani: Arabic and international Journalizim, UAE, ALAin,ALkitab ALjamei, pwess, r.lı, prll-rl.

(10) Mamdouh Mobarak ALRAUD: The Role of networks in political chang, in Tunisia and Egypt, from The Point of View of Jordanian journalists(Not published), Master research, ALsharq ALAwsat University, r.1r, pp $\leqslant q-\varepsilon \wedge$.

(1४) Cha, M., Kwak, H., Rodriguez, P,Ahn, Y.-Y. \& Moon, S. I tube, you tube, everybody tubes: analyzing the world's largest user generated content video system. Paper presented at the Proceedings of the $v$ th CMSIGCOMMConference on Internet measurement, San Diego, CA, October, $r_{\cdots} \cdot v, p^{r} \varepsilon_{-} r r$.

(iv) Jamal ABdulaziz ALsharhan:Educational aids and deuelopments in eduqational technolog, $V^{r}$, Riyadh, ALhumaithi press, ${ }^{+. .1}, p^{10 V}$.

( 1 ) Mashara Nur ALdin: The Role of Marketing across networks in customer relationsh: management, case study of mobile phone dealers in Algeria,(not published), Master research, institute of Economic, Commercial and Allied sciences, kasidi Mirbah universityWaraqla, r. ${ }^{\prime} \leqslant, p^{q}$.

(19) Samaah Mohammed Hamdi: The impact of the Egypt public exposure of Face book ads on the dicision to buy, scientific Magazine of Journalizim research, $V^{\Upsilon}$, Media college, cairo university, r.10, prr.

(r.) Khalid ALUmari: Amun prophecy, The Internet from the cold war to the Fourth generation wars and the Fabli of generations, Cairo, ALahram press, r.l $p^{\prime 11 r}$.

(r) Pronin, E., Lin, D. Y. \& Ross, L. The bias blind spot: Perceptions of bias in self versus others. Personality and Social Psychology, no r^, Bulletin, r..r $, p, r$ rq.

(rr) Marwa Mohi said ALahi: Commercial advertisements on social net working sites and their relation to the consumer behauior of students of Egyptian universities, (not

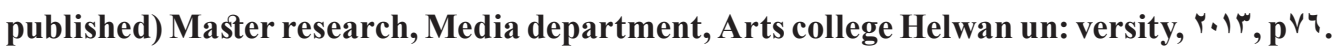

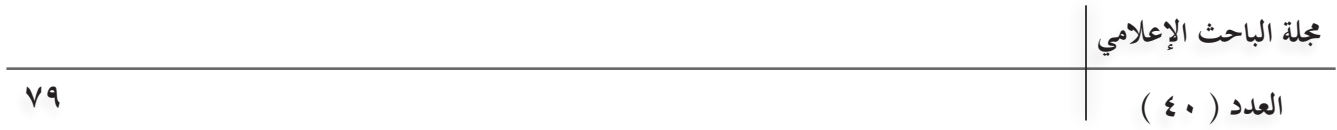


(Yr) Jamal Sanad AL-siwid: social Media and its Role in future transformations from tribal to Facebook, Abu dhabi, AL-Emarat Center of strategic studies and Reserches, r.lr, p^r.

( $Y$ \&) Solis, B. (ed), Engage: The Complete Guide for Brands and Businesses to Build, Cultivate, and Measure Success in the New Web, 'st edn, John Wiley \& Sons, New York. r. ${ }^{\prime \prime}, p^{\prime r}$.

(ro) JustinLivi: shopping Through Face book, translated by khaled Taha AL-khaled, Beirut, ALdar ALRabia for science(Nashiroun), r.ll. P 11 .

(Y⿱) Safwat AL-ALim: The process of advertising communication, V, Cairo, ALNohtha ALARabia press, $r^{\cdots} \cdot v, p^{r}$.

( $r v)$ Usuf Huchaim sultan AL-tai and Hashim fawzi dabbas AL-Abadi:The Electronic shopping, Amman, Dar ALwarraq,press, r..q,pp rVV-rVฯ.

$\left({ }^{\wedge}\right)$ Bernar Boleia: The end of the newspapers and the future of the Media,Translated by khaled Taha ALkhaled, Beirut, AL-Dar ALArabia press(Nashiroun), r.11, p 01 .

(rq) ANAGNOSTOPOULOS, A.,KUMAR, R., AND MAHDIAN, M. Influence and correlation in social networks. In Proceedings of the Is th Internal Conference on

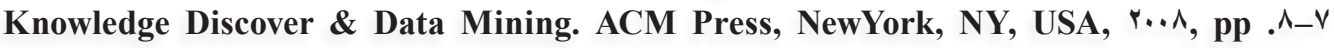
(r.) Mohammed Abu Samra: Advertising Management. Amman, Dar Usama press, r.. q, pp $1 \leqslant q-1 \leqslant \Lambda$.

(rl)Muhsin Fathi Abdalsabour: The secrets of promotion in The age of Globalization, Cairo, ALNile group press, $r_{\ldots} \cdot$ l, $\mathbf{p}^{\wedge}$.

(rr)Jansen, B.J., Zhang, M.M., Sobel, K., \& Chowdury, A. The commercial impact of social mediating technologies: micro-blogging as online word of mouth branding. $\mathrm{CHI}$ ' 9 Proceedings of the $r v$ th International Conference Extended Abstracts on Human Factors in Computing Systems, Boston, MA, April १-₹, Association for Computing Machinery (ACM), New York, NY, r...q, p, r^.

$\left(r^{r}\right)$ Laila Hafiz: shopping through Internet, the ${ }^{r}$ st century project, Journal of Marketing and advertising, No: ₹, first year, 199^, $p^{\wedge}$.

( ${ }^{\Psi}$ \&) Morwa shibl, Ojaiza:Online Advertising Technology, Cairo, Dar AL-ALam ALARabi press, $r \cdot 1 \cdot, p p \vee \varepsilon-\vee r$.

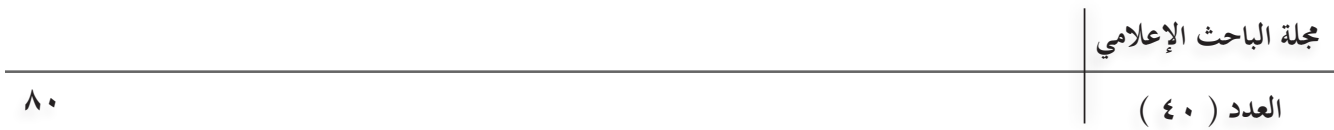

